УДК 547.913: 543.544.45: 543.51:543.429.23

\title{
ПРОБЛЕМЫ КАЧЕСТВЕННОГО И КОЛИЧЕСТВЕННОГО АНАЛИЗА ЛЕТУЧИХ ВЕЩЕСТВ РАСТЕНИЙ
}

\author{
(C) А.В. Ткачев
}

\author{
Новосибирский институт органической химии им. Н.Н. Ворожцова \\ Сибирского отделения Российской академии наук (НИОХ СО РАН), \\ пр. Академика Лаврентьева, 9, Новосибирск, 630090 (Россия) \\ Новосибирский государственный университет (НГУ), ул. Пирогова, 2, \\ Новосибирск, 630090 (Россия), e-mail: atkachev@nioch.nsc.ru
}

За последние 15-20 лет значительно изменились стратегии анализа летучих веществ растений вследствие внедрения новых подходов к пробоподготовке и анализу, в том числе и подходов, разработанных для других областей и применяемых в настоящее время к анализу растительных веществ. Любой анализ растительных веществ состоит из двух этапов. Первый этап - это сбор, первичная обработка, консервация, хранение и экстракция растительного материала с целью подготовить пробы для исследования. Второй этап - это собственно анализ подготовленных проб с использованием того или иного набора хроматографических, спектральных и/или гибридных методов. Зачастую в научных публикациях внимание сосредоточено на втором этапе, а то, что происходит с биоматериалом на первом этапе, находится «за кадром». Однако именно на первом этапе происходят значимые процессы, без учета которых невозможно правильно и адекватно оценить конечный результат выполненного исследования. На обоих этапах исследовательской работы возникают специфические проблемы, обсуждению которых и посвящен настоящий обзор.

Широкое распространение новейшего газохроматографического оборудования, оснащенного современными программными средствами, привело к тому, что значительная часть эксперимента осуществляется в автоматическом режиме. Однако надо понимать, что совершенствование техники эксперимента не меняет основ метода, а потому не устраняет принципиальных ограничений данного метода исследования. Поэтому хроматографические или хроматомасс-спектрометрические данные, получаемые в автоматическом режиме, должны быть подвергнуты беспристрастной ревизии со стороны экспериментатора с учетом всех известных ограничений, свойственных тому или иному хроматографическому методу разделения или детектирования компонентов, чтобы избежать ошибок при публикации результатов. Для правильной интерпретации получаемых данных необходимо знать всю историю анализируемого образца, а для этого все манипуляции с растительным материалом - от сбора сырья и до финальной пробоподготовки - должны быть самым тщательным образом задокументированы. Только в этом случае можно рассчитывать на получение значимых результатов исследования.

Ключевые слова: летучие вещества растений, газовая хроматография, хромато-масс-спектрометрия, качественный анализ, количественный анализ, детекторы, стандарты, артефакты.

Работа выполнена в рамках проекта № 0302-2016-0005 (V.46.1.3.) «Высокотехнологическая аналитическая платформа для исследований в области фармакогнозии, фитохимии, клинической и экспериментальной медицины, химической экологии и для обеспечения экологической, фармацевтической и продовольственной безопасности» на 2017-2020 г2.

\section{Оглавление}

Введение 6

Нативные компоненты или артефакты? .................................................... 7

Предварительная подготовка растительного сырья .................................... 7

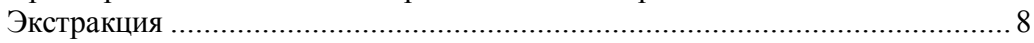

Жидкостная экстракция........................................................ 8

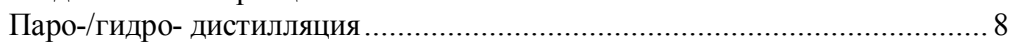

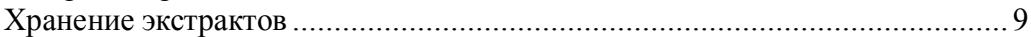

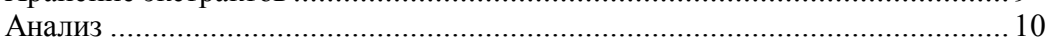

Ткачев Алексей Васильевич - заведующий лабораторией терпеноидных соединений, доктор химических наук, професcop, e-mail: atkachev@nioch.nsc.ru 


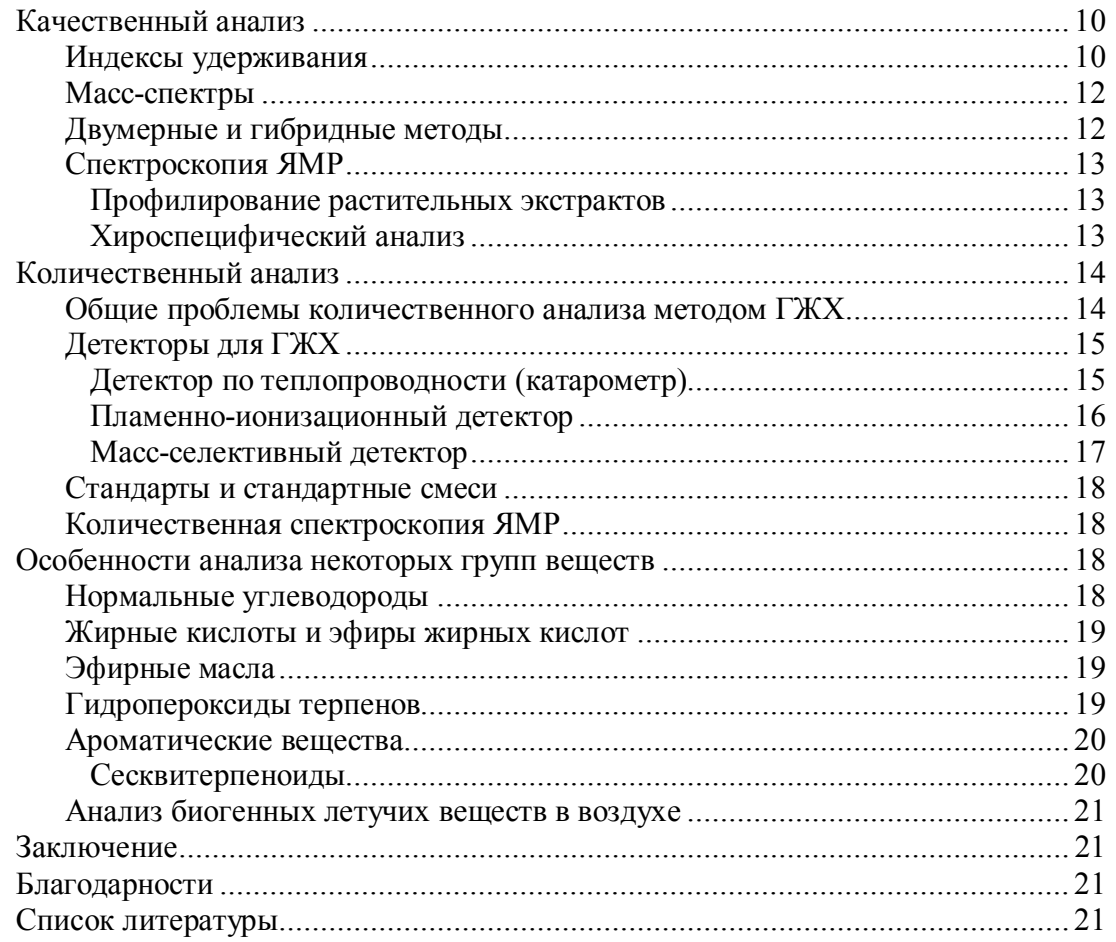

\section{Введение}

Растения обладают способностью синтезировать, накапливать и выделять во внешнюю среду летучие компоненты, представляющие собой гетерогенную группу низкомолекулярных веществ, которые имеют молекулы с насыщенными и ненасыщенными, линейными и разветвленными цепями и циклическими фрагментами, несущими различные функциональные группы (гидроксильные, карбонильные, эфирные, карбоксильные и др.). Важное место среди таких веществ занимают терпеноиды (изопреноиды), представленные в природе более чем 40000 структур и образующие самый большой класс всех известных метаболитов растений [1]. Основные пути биосинтеза летучих веществ к настоящему времени известны, и установлено большое количество генов, кодирующих ферменты, участвующие в образовании летучих веществ [2]. Многие вещества этого типа являются коммерчески важными и используются в пищевой, фармацевтической, сельскохозяйственной и химической промышленности. Особое внимание уделяется изучению малых молекул, которые играют центральную роль в биологии, являясь медиаторами многих ключевых процессов, таких как обмен веществ, трансдукция различных сигналов, спаривание и химическая защита. Маленькие молекулы определяют рядом традиционных категорий: метаболит, вторичный метаболит, феромон, гормон и т.д. Вместе с тем эти категории часто перекрываются, и одно соединение может появляться под более чем одним функциональным заголовком. Поэтому в целях унификации все чаще используется термин «малые биогенные молекулы» ${ }^{1}$, чтобы описать любую небольшую молекулу из биологического источника. Знания о структуре и относительных количествах летучих веществ, выделяемых растениями, имеет большое значение для многих разделов фундаментальных и прикладных исследований в области биологии, химии и смежных дисциплин. Получение этих знаний требует изучения профилей летучих веществ растений и преодоления многих связанных с этим аналитических проблем, поскольку летучие вещества растений представляют собой сложные смеси разнородных по структуре и свойствам компонентов. Две основные области химических исследований растительных метаболитов - химия природных соединений и метаболомика - имеют отношение к химическому профилированию растительных объектов [3]. Исследование летучих веществ растений требует применения аналитических методов и технологий, с помощью которых можно было бы не только полностью оценить состав летучих веществ, но также контролировать изменения профиля изучаемых компонентов и обнаруживать следовые количества веществ, характеристичных для данного вида растений. Стратегии анализа значительно изменились за последние 15-20 лет из-за внедрения новых подходов к пробоподготовке и анализу, в том числе и подходов, разработанных для других областей

\footnotetext{
${ }^{1}$ англ.: biogenic small molecules - BSM.
} 
и применяемых в настоящее время к анализу летучих веществ растений. В обзорах [4-7] дается краткий обзор продвижения аналитических методов и того, как они могут влиять на стратегии и подходы к изучению летучих веществ растений.

Любой анализ растительных веществ состоит из двух этапов. Первый этап - это сбор, первичная обработка, консервация, хранение и экстракция растительного материала с целью подготовить пробы для исследования. Второй этап - это собственно анализ подготовленных проб с использованием того или иного набора хроматографических, спектральных и/или гибридных методов. Зачастую в научных публикациях внимание сосредоточено на втором этапе, а то, что происходит с биоматериалом на первом этапе, находится «за кадром». Однако именно на первом этапе происходят значимые процессы, без учета которых невозможно правильно и адекватно оценить конечный результат выполненного исследования. На обоих этапах исследовательской работы возникают специфические проблемы, обсуждению которых и посвящен настоящий обзор. Первому блоку проблем посвящен раздел «Нативные компоненты или артефакты?», а проблемы второго блока затрагиваются в последующих разделах («Качественный анализ», «Количественный анализ», «Особенности анализа некоторых групп веществ»).

Первая проблема, с которой сталкивается исследователь, занимающийся изучением растительных метаболитов, - это проблема извлечения и концентрирования растительных веществ, многие из которых являются чрезвычайно лабильными и легко претерпевают разнообразные химические превращения вне тканей растения. В настоящее время не существует методов качественного и количественного определения растительных веществ непосредственно в интактных тканях растений, а любой метод извлечения и концентрирования либо искажает состав нативных компонентов, либо приводит к образованию артефактов - веществ, которых изначально не было в исследуемом материале и которые образовались из каких-то природных веществ в ходе экстракционных процедур и пробоподготовки.

\section{Нативные компоненты или артефакты?}

Существует две причины появления артефактов в ходе исследования растительного сырья — это ошибки и погрешности в ходе экспериментальной работы и нестабильность исследуемых компонентов в ходе выполняемых экспериментов.

Что касается экспериментальных «ошибок», то для того чтобы избежать их, следует учитывать накопленный другими исследователями опыт и понимать главные причины их возникновения. Издан энциклопедический каталог ловушек и проблем, с которыми сталкиваются все аналитики в своей работе, использующие различные спектрально-аналитические и хроматографические методы (ГЖХ, масс-спектрометрия, ВЭЖХ, ТСХ), и посвященный, по словам автора, «бесчисленным ученым, которые совершали ошибки, применяли нечистые химические вещества и растворители, страдали последствиями непредвиденных побочных реакций и иным образом появляющегося исследовательского хаоса, но были слишком смущены, чтобы опубликовать свои выводы» [8].

Однако даже при «правильной» работе и соблюдении всех предписанных процедур для извлечения растительных метаболитов [9] избежать появления артефактов бывает невозможно, и лабильные природные соединения подвергаются химическим превращениям на разных этапах выполнения исследований: (1) в ходе предварительной подготовки растительного сырья (сбор, транспортировка, сушка, измельчение и т.д.), (2) при извлечении (экстракции) растительного сырья, (3) при хранении готовых экстрактов, (4) при выполнении анализов.

\section{Предварительная подготовка растительного сырья}

Срезка растения при заготовке имеет результатом то или иное повреждение тканей, что вызывает нарушение нормальной жизнедеятельности растения и образование стресс-метаболитов [10, с. 19] — то есть веществ, которых в норме не было в растении. Постепенное угасание всех жизненных функций растения в ходе сушки растительного сырья приводит к изменению баланса ферментативных превращений, что вызывает нарушение нормального биосинтеза и вызывает ферментативные превращения нативных компонентов, не свойственные живому растению. Состав природных веществ, находящихся в высушенном растительном сырье, меняется со временем, несмотря на то, что все ферментативные процессы остановлены обезвоживанием. В этом случае вторичные процессы обусловлены постепенным улетучиванием самых «легких» компонентов, а также фотоиндуцированными и окислительными превращениями, протекающими в тканях под действием света и из-за диффузии кислорода воздуха. Например, при изучении состава образ- 
цов укропного масла, полученных из свежесобранного сырья и сырья, высушенного на воздухе обычным образом и методом лиофильной сушки, показано, что в ходе переработок не только появляются артефакты, но и исчезают некоторые компоненты. Так, высушенный на воздухе укроп дает в 10 раз меньше эфирного масла по сравнению со свежей травой, причем из эфирного масла практически полностью исчезают производные бензофурана - важнейшие пахучие компоненты укропа [11]. Примеры различий составов летучих веществ для различных дикорастущих растений при разных сроках хранения сырья приведены в работе [12]. В исследовании [13] изучены изменения метаболических профилей можжевельника (Juniperus monosperma (Engelm.) Sarg.) в зависимости от характера обработки сырья в соответсвии с тремя протоколами: после срезки растительный материал (А) помещали на сухой лед на 5 часов и далее хранили при $-80{ }^{\circ} \mathrm{C}$ в течение 3 недель (контроль); (В) выдерживали при обычной (комнатной) температуре в течение первых 24 ч, а затем замораживали до $-80{ }^{\circ} \mathrm{C}$ и хранили при этой температуре в течение 3 недель; (В) выдерживали при обычной (комнатной) температуре в течение первых 24 часов, а затем хранили при $+8{ }^{\circ} \mathrm{C}$ в течение 3 недель. В результате исследования показано, что продолжительность хранения срезанных побегов можжевельника не должна превышать 3 недель, а температура хранения холодильного оборудования должна быть ниже $+8^{\circ} \mathrm{C}$, в противном случае профили терпеновых компонентов значительно искажаются по сравнению с контролем.

При исследовании летучих веществ можно использовать свежесобранное растительное сырье, но для этого необходимо выполнять пародистилляцию и все первичные манипуляции с экстрактами в полевых условиях на месте сбора сырья [14].

На практике очень непросто организовать работы в полевых условиях так, чтобы можно было «законсервировать» растительное сырье или свежеприготовленные экстракты. Поэтому большей части исследователей приходится довольствоваться работой с высушенным сырьем и, таким образом, сознательно иметь дело с измененным составом метаболитов при наличии вторичных продуктов и артефактов.

\section{Экстракция}

Выделение нестабильных природных соединений сопряжено с рядом проблем, которые возникают в ходе извлечения и выполнения анализов. Различные техники разделения с использованием отдельных приемов или их комбинаций обсуждаются в работе [15]. Вместе с тем типичные, ставшие очень популярными методы извлечения растительных веществ в силу специфики используемых процедур неизбежно приводят к образованию артефактов [9]. Пероксиды представляют собой очень важную группу природных соединений $[16,17]$, многие из которых являются важными биологически активными веществами [18-20]. Выделение и анализ этих соединений сопряжены с известными трудностями, связанными с нестабильностью перекисных соединений.

\section{Жидкостная экстракиия}

Эксперименты по жидкостной экстракции выполняется, как правило, с предварительно высушенным сырьем, в тканях которого все мембраны либо полностью разрушены, либо потеряли свои исходные свойства. Экстракция малополярными органическими растворителями (гексан, петролейный эфир, бензин, ароматические и хлорированные алифатические углеводороды) бензол, относительно безобидна с точки зрения химического воздействия на природные компоненты, в то время как спирты и смеси органических растворителей с водой могут вызывать изменения некоторых нативных компонентов. Основные проблемы в этом случае связаны с частичным гидролизом некоторых групп веществ (сложные эфиры и гликозиды различной природы), этерификацией и переэтерификацией [9, 21-23]. Особые проблемы связаны с наличием некоторых специфических примесей, в особенности - в хлорированных органических растворителях; использование таких растворителей приводит к образованию известных групп артефактов [9].

Паро-/гидро- дистилляцчия

Самый простой и самый распространенный способ извлечения эфирных масел - это гидро- или пародистилляция. Хорошо известно, что некоторые компоненты эфирных масел не присутствуют как таковые в растениях, а являются артефактами процесса экстракции. Такие артефакты могут быть продуктами либо ферментативного расщепления, либо химического разложения, происходящего при нагревании в присутствии воды и связанного с деструкцией лабильных и высокомолекулярных соединений. Растительные ткани содержат то или иное количество низших органических кислот, это приводит к тому, что гид- 
ро/пародистилляция всегда протекает в слабокислых условиях, что неблагоприятным образом сказывается на сохранности нативных компонентов. Так, если сам линалоол не разлагался в диапазоне $\mathrm{pH} 5,0-8,0$, то аллильная перегруппировка линалилацетата легко протекает даже при pH 7,0, не говоря уже о слабокислых условиях, поэтому объекты, содержащие линалилацетат, всегда являются очень сложными для анализа изза наличия артефактов [24]. Часто компоненты эфирных масел являются продуктами гидролиза соответствующих гликозидов, как, например, для розового масла [25] и многих других эфирных масел [26-30].

При гидро/пародистилляции нативные компоненты растительного сырья экстрагируются из тканей за счет диффузии или высвобождаются в ходе разрушения специализированных секреторных структур [14, c. 19-26]. Чаще всего летучие вещества растений обнаруживаются в железистых трихомах (в русскоязычной литературе - эфирномасличных желёзках), которые являются группой разнообразных по морфологии анатомических структур [31], специализирующихся на синтезе и секреции определенных веществ [32], причем не только летучих [33].

Прямой отбор проб из секреторных структур и анализ полученных образцов показал драматические различия в качественном и количественном составе эфирного масла, получаемого путем гидро/пародистилляции, и содержимым железистых трихом [34, 35]. Окончательный вывод по результатам этих исследований звучит неутешительно: анализ эфирных масел в основном представляет собой анализ артефактов, образующихся при дистилляции и газохроматографическом эксперименте.

Основные пути образования артефактов связаны с термическими, гидролитическими и окислительными процессами, а также фотоиндуцированными и кислотно-катализируемыми превращениями в процессе извлечения. Основными известными группами артефактов являются хамазулен и родственные соединения, спатуленол [36], продукты гидролиза фосфолипидов и гликозидов, продукты разрешения хлорофилла и биополимеров кутикулы - кутина [37] и кутана [38] и других эпикутикулярных компонентов [39, 40]. Основные пути образования артефактов и главные группы артефактов обсуждаются в руководстве по изучению летучих веществ растений [10, ст. 194-220]. Известные артефакты разных структурных групп упоминаются в монографии по эфирным маслам [41] на страницах 7, 45, 53, 145, 175 и 182.

Известно большое количество гидропероксидов терпеновых производных, которые являются артефактами и обнаруживаются в терпен-содержащих продуктах. Так, различные монотерпены используются в косметике и парфюмерии для придания приятного аромата различным композициям. Однако наиболее часто используемые терпены легко окисляются при контакте с воздухом, образуя гидропероксиды, которые являются сильнодействующими сенсибилизаторами кожных покровов [42]. Аллергенная активность доказана для окисленных производных линалоола [43-45], линалилацетата [46, 47], лимонена [48-52], коричного спирта [53], цитронеллола [54]. Установлено, что скорость образования аллергенных гидропероксидов одинакова при окислении терпенов как в чистом виде, так и в составе эфирного масла (на примере лавандового масла) [55].

\section{Хранение экстрактов}

В период времени между получением образца (экстракта) и его анализом состав выделенных веществ может претерпеть изменения, характер и глубина которых зависит от способа хранения образца. Изменения в составе растительных экстрактов лучше всего изучены на примре эфирных масел, многие из которых являются коммерчески доступными продуктами [41], поэтому вопросы сохранности их состава и свойств имеют первостепенное значение.

Эфирные масла являются сами по себе довольно нестабильными субстанциями, в которых происходят спонтанные химические реакции, приводящие со временем к изменению химического состава. Изменение профиля летучих веществ и образование артефактов при хранении доказано для цитрусовых масел $[56,57]$, причем после хранения на холоду $\left(-21^{\circ} \mathrm{C}\right)$ в течение 12 месяцев существенных изменений не обнаружено, а после выдерживания при комнатной температуре $\left(+20.5^{\circ} \mathrm{C}\right)$ соотношение компонентов драматически меняется и дополнительно образуются множество артефактов. Так, после хранения масла из Citrus aurantium обнаружено 34 артефакта, составляющие в сумме 17\% всех летучих соединений [57]. Основными артефактами оказались (+)-карвон, транс,транс-фарнезилацетат, сабиненгидрат, 1-октен-3-ол, цุис,циисфарнезилацетат и дигидрокарвеолацетат. В работе [58] исследовали химический состав эфирного масла Помело (Citrus maxima) в связи с ухудшеним аромата при хранении. Показано, что появляющиеся неприятные ноты запаха связаны с накоплением окисленных производных линалоола и лимонена, для образования 
которых критичным является одновременное воздействие кислорода воздуха и солнечного света. В работе [59] обсуждается наиболее адекватные наборы аналитических параметров для отслеживания химических изменений во время хранения эфирного масла. Исчерпывающие сведения о возможных изменениях эфирных масел и факторах, влияющих на их стабильность, содержатся в обзоре [60], где описаны различные пути деградации при воздействии внешних параметров и аналитические методы оценки как истинных, так и измененных профилей эфирного масла. Доминирующую роль в образовании артефактов при хранении связывают с окислительными процессами, часть из которых можно затормозить добавкой антиоксидантов [61].

По нашему собственному опыту, подавляющее большинство образцов эфирных масел, запаянных в стеклянные ампулы, при хранении в темноте при температуре $5-8{ }^{\circ} \mathrm{C}$ годами не изменяют свой состав ${ }^{2}$. Исключение составляют, как правило, образцы эфирных масел, которые содержат значительные количества органических кислот: в таких случаях даже при условии «правильного» приготовления и надлежащего хранения возможны разнообразные кислотно-катализируемые превращения, искажающие исходный состав.

\section{Анализ}

Некоторые компоненты растительных экстрактов, будучи достаточно стабильными в ходе выделения, не поддаются обычному газохроматографическому анализу из-за недостаточной термостабильности. Давно известен пример превращения бициклогермакрена в бициклоэлемен за счет перегруппировки Коупа при нагреве [62]. Вообще гермакрановые соединения, как правило, являются термолабильными и претерпевают различные превращения в ходе газохроматографических экспериментов [63, 64], с чем связаны известные трудности их количественного анализа [65].

Методы газовой хроматографии непригодны также для анализа гидропероксидов из-за их термолабильности, поэтому в работе [66] сравнивались различные способы ионизации для обнаружения гидроперкосидов методом жидкостной хроматографии-масс-спектрометрии и показано, что состав подвижной фазы и настройки оборудования оказывают большое влияние на эффективность ионизации этих соединений.

Отчасти проблема термолабильности может быть решена за счет так называемого «холодного ввода» в газохроматографическую колонку, чтобы избежать теплового стресса вследствие нагрева в испарителе [34].

Удобным дополнением, а иногда - альтернативой является спектроскопия ЯМР, которая позволяет детектировать и выполнять количественный анализ чувствительных к нагреву компонентов.

\section{Качественный анализ}

В обзоре [67] представлено общее состояние качественного анализа в рамках хроматографического анализа. Газовая хроматография признана наиболее подходящей методикой для анализа сложных смесей биогенных летучих соединений, таких как цветочные ароматы и эфирные масла [68]. Бегло анализ эфирных масел методами газовой хроматографии рассмотрен в работе [69].

В связи с массированным использованием газовой хроматографии для рутинного анализа эфирных масел, возникает проблема оптимизации процедур анализа и сокращения их продолжительности. Разработан метод быстрой газовой хроматографии ${ }^{3}[6,70,71]$, который позволяет сократить время анализа примерно в 10 раз (с обычных 30-40 мин до 3-4 мин) при использовании укороченных капиллярных колонок длиной около 10 м и быстрого нагрева до 40 \%мин.

\section{Индексы удерживания}

Удерживание является одной из основных хроматографических характеристик вещества в ходе хроматографического анализа. Общепризнанная в настоящее время мера удерживания - это индекс удерживания. Техника вычисления индексов удерживания различна при хроматографировании в изотермическом режиме и в режиме линейного программирования температуры. Индексы удерживания для изотермического режима носят название индексов удержсивания Ковача (индексы Ковача) [72]. Индексы Ковача зависят от температуры [73] и типа неподвижной фазы. Современная средняя межлабораторная воспроизводимость индексов Ковача составляет около 5-10 единиц для стандартных неполярных фаз и 10-25 единиц для стандартных полярных фаз [74]. В условиях линейного программирования температуры времена удерживания

\footnotetext{
${ }^{2}$ Сказанное относится только к «правильно» приготовленным образцам, которые тщательно высушены и полностью освобождены от остатков осушителя.

${ }^{3}$ англ.: Fast-GC.
} 
гомологов увеличиваются линейно с увеличением числа атомов углерода в молекулах, поэтому становится возможным использовать линейную интерполяцию и абсолютные времена удерживания. Индексы удерживания в условиях линейного программирования температуры называют линейными индексами удерживания, которые вычисляются проще, чем индексы Ковача [75]. Линейные индексы удерживания в настоящее время очень широко используются в идентификации летучих компонентов растительных экстрактов, а границы их применимости показаны специальными исследованиями [76]. Индексы удерживания, вычисленные на основании экспериментов в режиме линейного программирования температуры зависят от профиля программирования температуры. Важно помнить, что изотермические индексы Ковача и индексы удерживания, полученные в режиме программирования температуры, несоизмеримы и непропорциональны, а линейные индексы удерживания, полученные в разных температурных режимах, могут очень сильно отличаться друг от друга [10, с. 89-90]. Поэтому следует с очень большой осторожностью использовать приведенные в литературе данные.

Рекомендуемый метод получения воспроизводимых газохроматографических профилей («отпечатков пальцев» летучих веществ) методом газовой хроматографии на неполярных стационарных фазах состоит в регистрации хроматографммы в условиях линейного программирования температуры со скоростью $4{ }^{\circ} \mathrm{C} /$ мин в диапазоне 50-250 ${ }^{\circ} \mathrm{C}$ [77]. Именно в таких условиях измерены индексы удерживания для колонки HР-5ms, которые приведены в руководстве [10]. Существуют другие библиотеки индексов удерживания, например, библиотека с индексами для колонки DB-5 при скорости нагрева $3{ }^{\circ} \mathrm{C} /$ мин в диапазоне $60-246{ }^{\circ} \mathrm{C}$ [78] и библиотека программы MassFinder 4, где приведены индексы удерживания на колонке DB-1 без указаний на режим (режимы) программирования температуры.

Особенности индексов удерживания, получаемых в режиме программирования температуры, и связь этих индексов с термодинамическими параметрами компонентов обсуждаются в обзоре [79]. Порядок определения линейных индексов удерживания при анализе летучих веществ растений изложен на с. 78-91 руководства [10].

Определение индексов удерживания - первичный этап идентификации при анализе методом газовой хроматографии относительно простых смесей соединений. Анализ очень сложных смесей с множественными перекрываниями хроматографических пиков требует более изощренных подходов. Один из таких подходов - двумерная газовая хроматография (GC×GC. 2D GC) [80]. Особенности инструментального обеспечения двумерной газовой хроматографии диктуют свои особенности в анализе и интерпретации индексов удерживания. Предложена схема выполнения анализов с картированием индексов удерживания: для первой и второй осей пространства двумерного анализа разработан способ создания корреляционной карты удерживания. В первом измерении генерируются линейные индексы удерживания, в то время как второе измерение может интерпретироваться на основе «псевдоизотермических» индексов удерживания [81].

Для многих компонентов сложных смесей природных продуктов значения индексов удерживания часто неизвестны, поэтому возникает необходимость предсказывать хроматографическое поведение определённых компонентов [82]. В ранних работах на эту тему было показано, что индексы удерживания душистых веществ при газохроматографическом анализе на неполярных и полярных стационарных фазах могут быть предсказаны с 3,6 и 5,6\% соответственно [83]. Развиваются подходы к предсказанию параметров удерживания в рамках моделей $\mathrm{QSAR}^{4}$ [84]. В обзоре [74] обсуждается связь структуры молекул и параметров удерживания для разных типов хроматографии, причем отмечается, что важнейшим является выбор дескрипторов (набора дескрипторов), поскольку не все физико-химические дескрипторы хорошо коррелируют с данными удержания, а самый простой расчетный параметр - теплота образования не связана с хроматографическим удерживанием. Наиболее полная коллекция молекулярных дескрипторов и представляет подробный обзор от истоков этой области исследований до наших дней. Этот практически ориентированный справочник дает подробный обзор различных представлений молекулярных дескрипторов и их соответствующих молекулярных дескрипторов [85]. Расчетные (прогнозируемые) значения индексов ухудшается по мере увеличения полярности стационарной фазы [74]. Как показано на примере спиртов и сложных эфиров, время удерживания компонентов можно прогнозировать для определенных стационарных фаз в температурном интервале $70-140{ }^{\circ} \mathrm{C}$ на основе молекулярных дескрипторов, реализованных в программе $\operatorname{CODESSA}^{5}$ [86].

\footnotetext{
${ }^{4}$ QSAR - Quantitative Structure-Activity Relationship.

${ }^{5}$ CODESSA $^{\mathrm{TM}}$ - Comprehensive Descriptors for Structural and Statistical Analysis. (http://www.semichem.com/codessa/).
} 


\section{Масс-спектры}

Наиболее широко используемым методом исследования и анализа летучих и условно летучих вторичных метаболитов растений является газовая хроматография с масс-спектрометрическим детектированием [68]. Газовая хроматография в комбинации с масс-спектрометрией электронного удара получила в последние десятилетия чрезвычайно широкое распространение и стала рутинным методом исследования состава летучих и условно летучих растительных веществ. Получаемые в этом методе масс-спектры являются мощным инструментом для идентификации компонентов сложных смесей. Вместе с тем использование масс-спектрометрического детектора в газовой хроматографии порождает ряд проблем, главная из которых - ограниченная воспроизводимость масс-спектров электронного удара в условиях газовой хроматомасс-спектрометрии. Масс-спектры одного и того же вещества, полученные электронным ударом при стандартной энергии ионизирующих электронов в 70 эВ на разных приборах, могут существенно различаться [87]. Более того, масс-спектры с одного прибора могут заметно отличаться, даже если зарегистрированы в строго контролируемых условиях. Ограниченная воспроизводимость связана, во-первых, с особенностями масс-спектрометрии как таковой [88] и, во-вторых, с конструктивными и эксплуатационными особенностями хромато-масс-спектрометрии как гибридного метода:

- при разной температуре источника ионов могут меняться относительные скорости распада (фрагментации) по разным направлениям, что приводит к изменению относительной интенсивности пиков в получаемом масс-спектре;

- давление в ионном источнике обычно выше оптимального для масс-спектрометрии, в результате чего, помимо обычных для масс-спектрометрии электронного удара мономолекулярных превращений, появляется заметное количество продуктов ионно-молекулярных реакций, что приводит к заметным отличиям получаемых масс-спектров от библиотечных спектров, зарегистрированных на «обычных» масс-спектрометрах;

- вид масс-спектра зависит от давления в ионном источнике, а это давление непостоянно в течение элюирования хроматографического пика, поэтому вид масс-спектра будет отличаться в зависимости от того, в какой точке хроматографического пика зарегистрирован масс-спектр - в начале, на вершине и на спаде.

Ограниченная воспроизводимость масс-спектров электронного удара накладывает отпечаток на идентификацию пространственных изомеров (диастереомеров), для многих из которых различия в массспектрах незначительны и не могут быть достоверно установлены из-за ограниченной воспроизводимости, и решающее значение приобретает газохроматографическая информация (индексы удерживания).

\section{Двумерные и гибридные методы}

Растительные экстракты содержат, как правило, очень сложный комплекс метаболитов, разделить которые в одном эксперименте не представляется возможным. Даже в случае если исследуемый образец содержит только летучие соединения, существуют области хроматограмм с очень «плотным» расположением хроматографических пиков с множественными наложениями пиков отдельных компонентов.

Серьезные трудности представляют собой смеси, содержащие природные сесквитерпеноиды. Сесквитерпеноиды содержатся, как правило, в относительно небольшом количестве в растительных объектах (по сравнению с моно- и дитерпеноидами), но играют исключительно важную роль в формировании запахов [89], при образовании вторичного атмосферного аэрозоля [90], как важные биологически активные компоненты растительных экстрактов [91-100]. Многие пары сесквитерпеновых соединений имеют очень близкие или даже совпадающие значения индексов удерживания, а многие соединения имеют практически неотличимые масс-спектры электронного удара $[10,78,101]$. Поэтому сесквитерпеновые соединения представляют собой очень сложный объект для исследований [102] .

Большие возможности для анализа очень сложных смесей растительных веществ предоставляют двумерные и гибридные методы [103], многие из которых стали важнейшим инструментарием для ускоренной идентификации известных компонентов смесей при поиске новых биологически активных соединений [104].

Одним из самых распространенных в настоящее время двумерных аналитических методов является двумерная газовая хроматография, позволяющая выполнять последовательное разделение с использованием хроматографических колонок с фазами разного типа [105]. Особый интерес представляет гибридный 
метод, сочетающий двумерную газовую хроматографию с масс-селективным детектированием $(\mathrm{GC} \times \mathrm{GC}-$ MS) [5]: в этом случае последовательное использование двух разных колонок сопровождается регистрацией масс-спектров разделяемых компонентов, что существенно облегчает и существенным образом повышает надежность идентификации компонентов в сложных смесях, что было продемонстрировано на примере анализа летучих веществ в экстракте листьев табака [106]. Двумерная газовая хроматография позволяет выполнять энантиоселективный анализ отдельных компонентов сложных смесей при использовании колонки с хиральным селектором во втором измерении [107, 108], а сводки экспериментальных данных о порядке элюирования энантиомеров в разных условиях [109] существенно облегчают анализ.

Последние достижения в области использования двумерной ГЖХ в анализе эфирных масел и душистых веществ даны в обзоре [7].

Двумерные и гибридные методы анализа часто порождают массивы данных, с которыми непросто работать. В обзоре [110] обсуждается использование методов факторного анализа в хроматографии при использовании современных гибридных методов.

\section{Спектроскопия ЯМР}

Спектроскопия ЯМР стала рутинным методом в исследовании структуры органических молекул, в том числе и веществ растительного происхождения. Вместе с тем неразрушающий характер умеренных температур анализа делают спектроскопию ЯМР незаменимой при обнаружении и идентификации неустойчивых и термолабильных соединений, таких как гермакрановые соединения [64] и соответствующие фуранодиенты [111], аскаридол [112], кислоты эвдесманового ряда [113], тритерпены [114], сесквитерпеновые лактоны [115]. Помимо этого компьютеризированные процедуры, основанные на спектроскопии ЯМР ${ }^{13} \mathrm{C}$ и использовании литературных данных, являются эффективным инструментом для идентификации соединений определенной группы в растительных экстрактах, что показано на примере соединений таксанового ряда [116].

Помимо этого спектроскопия ЯМР является дополнительным обязательным инструментом для идентификации компонентов очень сложных смесей и некоторых особых групп соединений.

\section{Профилирование растительных экстрактов}

Помимо традиционного использования в качестве метода установления структуры органических молекул спектроскопия ЯМР успешно применяется для изучения химического состава растительных тканей и живых растений $[117,118]$, а также при изучении наборов метаболитов любой сложности [119]. С помощью ЯМР удается визуализировать профили самого широкого спектра метаболитов из растительных тканей или клеток [120], поэтому ЯМР рассматривается как перспективный инструмент для профилирования метаболитов растений и обеспечивает получение информации, которая недоступна при использовании иных методов [121]. Достижения в области структурного анализа и изучения растительных метаболомов с использованием методов спектроскопии ЯМР высокого разрешения обобщены в обзоре [122]. Различные варианты спектроскопии ЯМР - мощный инструмент в спектральном профилировании лекарственных растений и фитопрепаратов [3].

\section{Хироспечифический анализ}

Спектроскопия ЯМР в ряде случаев является разумной альтернативой энантиоселективным хроматографическим методам, а иногда является единственным методом определения энантиомерной чистоты, когда разделения зеркальных изомеров не удается добиться хроматографическими методами.

Энанатиомерную чистоту монотерпеновых производных можно определять методом ЯМР ${ }^{13} \mathrm{C}$ с добавкой хирального реагента сдвига $\left(\mathrm{Yb}(\mathrm{hfc})_{3}\right)$ непосредственно в эфирном масле, как было показано на примере камфоры и фенхона [123] и борнилацетата [124], либо использовать метод ЯМР ${ }^{1} \mathrm{H}$ для предварительно выделенных соединений, как в случае анализа линалоола [125].

Спектроскопия ЯМР оказывается удобным методом определения энантиомерной чистоты конфигурационно неустойчивых соединений, таких как, например, гиосциамин, который имеет тенденцию к рацемизации в атропин в ходе экстракции, поэтому хроматографические методы дают искаженные результаты, и проблема решается методом ЯМР ${ }^{13} \mathrm{C}$ с добавкой хирального реагента сдвига $\left(\mathrm{Yb}(\mathrm{hfc})_{3}\right)$ [126]. Помимо хиральных реагентов сдвига можно использовать хиральные сольватационные реагенты, например, $(R)-(-)$ 2,2,2-трифтор-1-(9-антрил)этанол [127]. 
Обзор хиральных реагентов для определения абсолютной конфигурации органических молекул методом ЯМР приведен в работе [128], методология определения абсолютной конфигурации обсуждается в обзоре [129], а последние достижения в части распознавания энантиомеров с использованием ЯМР даются в работе [130].

\section{Количественный анализ}

Газовая хроматография является одним из немногих основных методов количественного анализа сложных смесей. При разработке методики количественного определения компонентов растительных экстрактов требуется проводить калибровку используемого оборудования, определять погрешность измерений и выполнять валидацию методики определения количественного содержания исследуемых компонентов.

Общие проблемы количественного анализа с помощью газовой хроматографии обсуждаются в руководстве [131]. Калибровка - это операция, главная цель которой состоит в установлении метрологического статуса измерительной системы. В результате аналитической калибровки находится эмпирическое соотношение, называемое измерительной функцией, которое позволяет впоследствии рассчитать значения количества вещества в образце из измеренных значений аналитического сигнала. Проблемы аналитической калибровки обсуждаются в работе [132], а проблемы количественного хроматографического анализа с использованием N-мерных калибровочных стратегий — в обзоре [133]. Как и у любого аналитического метода, в количественном анализе хроматографическими методами возникает проблема определения погрешности измеряемых величин. Источники систематических ошибок и методы их учета обсуждаются в работе [134]. С точки зрения методологии выполнения рутинных анализов проблематика определения погрешностей формулируется в работах [135-137], где обсуждаются различные аспекты обнаружения источников погрешностей и их учета при формировании окончательного результата измерений. Любой аналитический метод требует проверки. В работах $[138,139]$ обсуждается проблематика, связанная с валидацией аналитических методик и дается подробное пошаговое руководство по валидации аналитических методов, учитывая наиболее релевантные процедуры проверки с оценкой погрешности и точности измерений.

Проблемы калибровки, определения погрешностей и извлечения в ходе хроматографического эксперимента обсуждаются в обзоре [140]. В работе [141] дан критический обзор существующих методов количественной оценки компонентов эфирных масел. Рекомендации по количественной газовой хроматографии эфирных масел и душистых веществ содержатся в работе [142].

\section{Общие проблемы количественного анализа методом ГЖХ}

Проблемы количественного анализа методом газовой хроматографии давно и хорошо известны, разработано множество подходов к количественному анализу, которые подробно освещаются в специализированной литературе. На русском языке можно порекомендовать ряд руководств [143-145]. При выполнении анализов возникают проблемы чисто технического характера, связанные с интегрированием сигналов (погрешности в определении площадей малоинтенсивных пиков на фоне шумов, пики неправильной формы, наложение пиков, дефекты оцифровки...). Мы не будем останавливаться на этих технических проблемах, поскольку их решение описано в руководствах и технической документации к газохроматографическому оборудованию, но вкратце обсудим принципиальные моменты количественного анализа.

Количественный анализ хроматографическими методами выполняется в рамках двух допущений, а именно: (1) состав пробы, введенной в хроматограф, идентичен составу анализируемой смеси; (2) существует линейная зависимость между количеством вещества и интенсивностью (площадью) соответствующего хроматографического пика. Существует три метода количественного анализа с использованием газохроматографических экспериментов.

Метод абсолютной калибровки заключается в нахождении эмпирической зависимости площади хроматографического пика от количества вводимого в хроматографическую колонку вещества. Метод требует наличия стандарта - то есть образца известной чистоты того самого вещества, содержание которого определяется в ходе анализа. Метод требует точного соблюдения условий анализа (хроматографирования и детектирования) при выполнении калибровки и исследования неизвестного образца.

Метод внутренней нормализации состоит в том, что сумма площадей всех хроматографических пиков приравнивается к 100\%, а содержание отдельного компонента рассчитывается как относительная площадь соответствующего хроматографического пика. Такой метод применим только тогда, когда (1) хроматограмма содержит пики всех без исключения компонентов, присутствующих в анализируемой смеси, (2) 
чувствительность детектора одинакова в отношении всех анализируемых компонентов, (3) сигнал детектора линейно растет с увеличением количества вещества. На практике такого не случается никогда, поскольку почти всегда часть компонентов на хроматограмме не видна, а любой детектор имеет избирательную чувствительность. По этой причине метод внутренней нормировки в описанном варианте является лишь методом полуколичественной оценки содержания компонентов ${ }^{6}$. Простейший способ приблизить результаты анализа методом внутренней нормализации к реальному содержанию компонентов - это использовать в расчетах поправочные коэффициенты (градуировочные коэффициенты, коэффициенты чувствительности детектора), которые учитывают разную чувствительность используемого детектора по отношению к компонентам анализируемой смеси. Проблема в этом случае состоит в том, что необходимы поправочные коэффициенты для всех компонентов анализируемой смеси, что почти всегда невозможно выполнить экспериментально, и приходится прибегать к разного рода допущениям и приближениям.

Метод внутреннего стандарта заключается в сопоставлении площади хроматографического пика интересующего компонента анализируемой смеси с площадью хроматографического пика внутреннего стандарта - известного вещества, добавляемого к анализируемой смеси в известном количестве. Вычисление концентрации анализируемого компонента выполняется с учетом поправочных коэффициентов, учитывающих различную чувствительность детектора по отношению к внутреннему стандарту и анализируемому веществу. Преимуществом такого метода является то, что можно определить содержание выбранного компонента (или ряда выбранных компонентов) без знаний о том, что представляет собой вся остальная смесь. Недостатком метода является необходимость использования внутреннего стандарта, удовлетворяющему ряду известных требований, подобрать который для количественного анализа сложных смесей бывает непросто.

Метод стандартной добавки используют тогда, когда по каким-либо причинам не удается подобрать вещество для использования его в качестве внутреннего стандарта (см. выше). При таком методе к анализируемой смеси добавляют рассчитанное количество определяемого компонента, а содержание этого компонента в анализируемой смеси определяют сравнением исходной хроматограммы и хроматограммы с добавкой анализируемого компонента. Недостатками такого метода является следующее: (1) необходимо иметь стандартный образец анализируемого соединения или набор стандартных образцов для количественного анализа интересующих компонентов, (2) для определения содержания нескольких компонентов необходимо выполнить множественные эксперименты со стандартными добавками разных соединений.

\section{Детекторы для ГЖХ}

Для количественного анализа методом газовой хроматографии могут использоваться данные, полученные на разных детекторах, и в каждом случае необходимо понимать особенности и ограничения, присущие данному типу детектирования. Для получения количественных результатов необходимо использовать поправочные коэффициенты, которые являются функцией отклика детектирующего устройства на данное соединение [146]. Коэффициенты чувствительности, полученные для одного и того же детектора на разных приборах, варьируют в широких пределах. Коэффициенты чувствительности зависят не только от природы самого анализируемого вещества, но и от некоторых свойств анализируемой смеси и условий анализа. Так, факторы отклика различных монотерпенов меняются в зависимости от концентрации исследуемого вещества, причем зависимость от концентрации неодинакова для разных монотерпенов и меняется неочевидным образом при переходе от одного соединения к другому [147]. Для детектора электронного захвата коэффициенты чувствительности зависят от скорости потока газа-носителя, причем эта зависимость имеет очень сложный вид [148]. Коэффициенты чувствительности являются уникальными для данного метода детектирования и являются непереносимыми с одного типа детектора на другой. В некоторых случаях коэффициенты чувствительности уникальны для разных конфигураций оборудования с одинаковыми типами детектирующих устройств [149].

\section{Детектор по теплопроводности (катарометр)}

Детектор по теплопроводности (катарометр) ${ }^{7}$ [150], хотя и уступает большинству других детекторов по чувствительности, до сих пор является очень популярным в количественном анализе из-за своей уни-

\footnotetext{
${ }^{6}$ По этой причине в профильных журналах с упором на аналитическую составляющую (Flavour and Fragrance Journal) не принимаются к рассмотрению работы, в которых составы летучих веществ и эфирных масел получены методом простой внутренней нормализации.

7 англ.: Thermal Conductivity Detection (TCD), Katharometer.
} 
версальности. Оклик детектора по теплопроводности зависит от массового расхода газа-носителя, давления газа-носителя в измерительной ячейке, тока моста, температуры детектора и массы образца. При точном контроле всех этих параметров можно достичь очень высокой точности и воспроизводимости анализа [151]. Следует помнить, что относительный отклик этого детектора зависит от конструкции прибора, поэтому калибровка детектора по теплопроводности с использованием литературных значений коэффициентов чувствительности может привести к значительным погрешностям в определении концентраций [149].

Расчет относительных молярных коэффициентов отклика детекторов по теплопроводности в газовой хроматографии имеет долгую историю [152]. На примере анализа смесей метиловых эфиров жирных кислот методом газожидкостной хроматографии показано, что поправочные коэффициенты для количественного анализа не одинаковы для изотермического режима и режима с программированием температуры [153]. Для прогнозирования коэффициентов отклика детекторов по теплопроводности для разнообразных органических соединений может использоваться модель количественных соотношений структурасвойство (QSRR). Показано, что на основе ряда структурных дескрипторов (молекулярная масса, сумма длин связей, поляризуемость, электроотрицательность и др.) с помощью множественных линейных регрессий достигается высокая корреляция коэффициентов отклика с набором молекулярных дескрипторов. Разработанная модель позволяет выполнять количественное определение веществ, экспериментальные коэффициенты отклика которых неизвестны [154].

\section{Пламенно-ионизационный детектор}

Пламенно-ионизационный детектор (ПИД) ${ }^{8}$ является одним из самых распространенных детекторов в газовой хроматографии [150]. Хотя ПИД реагирует практически на все органические соединения, чувствительность этого детектора может меняться в 3-4 раза для соединений разных классов [155] и зависит от особенностей строения молекул исследуемых соединений [156]. При изучении коэффициентов чувствительности для 130 сложных эфиров органических кислот (этиловые, изопропиловые, $\mu$-пропиловые, изобутиловые и $н$-бутиловые эфиры жирных кислот $\mathrm{C}_{1}-\mathrm{C}_{20}$, алифатических дикарбоновых кислот $\mathrm{C}_{2}-\mathrm{C}_{12}$, a также бензойной и $о$-фталевой кислот), показано, что факторы отклика меняются в широких пределах: от 1,10 для этиловых эфиров жирных кислот до 3,67 для $н$-бутилового эфира о-фталевой кислоты [157]. Существуют определенные проблемы в количественном анализе низших жирных кислот в виде метиловых эфиров, поэтому в некоторых случаях бывает удобней их анализировать в виде более тяжелых эфиров, например, бутиловых [158]. Экспериментально определены факторы отклика для 10 монотерпенов с использованием $n$ цимола в качестве внутреннего стандарта и показано, что факторы отклика для исследованных соединений лежат в диапазоне 0,844-1,055. Исключение составили лимонен $(0,938-1,266)$ и мирцен $(0,681-0,813)$. Недооценка концентраций мирцена может быть связана с его склонностью к димеризации с образованием димирцена (камфорена) и полимеризации при температурах выше $200^{\circ} \mathrm{C}$ [147]. При анализе сложных смесей, содержащих много разных по структуре и свойствам терпеновых производных с неизвестными коэффициентами отклика, используют разделение всех компонентов на группы по степени подобия и калибровку по одному компоненту из каждой группы, например, 2-карен для монотерпеновых соединений и карвон для простейших окисленных производных [159]. Таким образом, удается достичь низких пределов обнаружения и достаточно высокой точности количественного анализа.

Предсказывать значения отклика ПИД можно с использованием различных подходов. Один из самых первых подходов такого типа, который совершенствуется до настоящего времени, основан на концепции эффективного углеродного числа ${ }^{9}[157,160-164]$.

В основе другого подхода лежит то обстоятельство, что при работе пламенно-ионизационного детектора происходит сгорание аналита, а значит, коэффициенты чувствительности могут зависеть от теплоты сгорания анализируемого вещества. Действительно, существует хорошая корреляция между относительными коэффициентами отклика и теплотами сгорания [165]. Поскольку в настоящее время теплоты сгорания любого органического вещества могут быть рассчитаны с достаточно хорошей точностью различными квантово-химическими методами, относительные коэффициенты чувствительности ПИД можно моделировать с удовлетворительной точностью, как было показано на примере летучих компонентов различных ароматизаторов [166]. На примере анализа силилированных производных биомолекул показано, что пред-

\footnotetext{
8 англ.: Flame Ionization Detector (FID).

${ }^{9}$ англ.: effective carbon number.
} 
сказание коэффициентов чувствительности на основе расчетных значений теплот сгорания является одним из немногих методов, позволяющих количественно определять летучие соединения без калибровки прибора с использованием чистого эталонного вещества [167].

Третий подход основан на использовании молекулярных дескрипторов, таких как, например, индекс внутренней молекулярной поляризуемости [168]. Предпринимались попытки моделирования факторов отклика пламенно-ионизационного детектора с использованием искусственной нейронной сети, и в результате проведенных исследований показано, что разработанная нейронная сеть обладает хорошей прогнозирующей способностью [169]. По данным множественной линейной регрессии, учитывающей различные дескрипторы молекул (молекулярная масса, число колебательных мод, площадь поверхности, индекс Балабана [170]), с использованием искусственной нейронной сети получен хороший прогноз значений коэффициентов отклика для соединений разных классов [171].

Показано, что гелиевый импульсно-разрядный фотоионизационный детектор ${ }^{10}$ является более точным по сравнению с ПИД при определении процентного состава смеси углеводородов. Кроме того, такой метод детектирования является более универсальным по сравнению с ПИД [172].

\section{Масс-селективный детектор}

Использование масс-спектрометра в качестве детектора для количественного анализа порождает самый обширный набор проблем [68, 88, 173]:

- чувствительность масс-спектрометрического детектора при регистрации полного масс-спектра обычно заметно ниже, чем у пламенно-ионизационного, при этом чувствительность массселективного детектора зависит в довольно широком диапазоне от метода ввода пробы [174];

- $\quad$ конечный динамический диапазон детектора (порядка $10^{6}$ ) приводит к тому, что в случае анализа сложных смесей либо появляются искаженные пики основных компонентов, либо слабоинтенсивные компоненты теряются в шумах. И то, и другое приводит к значительным ошибкам в интегрировании;

- конечная скорость работы магнитного анализатора (в современных устройствах с квадрупольным масс-спектрометром масс-спектры сканируются со скоростью 2-10 спектров в секунду), что приводит к неточной оцифровке хроматографического пика с последующей значительной ошибкой при определении интегральной интенсивности ${ }^{11}$;

- интенсивность возникающего ионного тока при прочих равных условиях определяется сечением ионизации, которая зависит от структуры (формы) молекулы и может изменяться в широком диапазоне. На практике это означает, что два вещества с разным сечением ионизации, попадая в ионизационную камеру в одинаковом количестве, дают разное количество ионов и, как следствие этого, — разную интенсивность суммарного ионного тока и разную площадь соответствующих хроматографических пиков;

- $\quad$ масс-анализатор любого типа в разной степени пропускает ионы с разными значениями $m / z$, поэтому если в камере ионизации образуется одинаковое количество ионов с двумя разными массами, то это не означает, что ионные токи, соответствующие этим массам в масс-селективном детекторе будут иметь одинаковую величину. Разница в интенсивности ионных токов будет тем больше, чем больше разница в значениях $m / z$. Разные типы масс-анализаторов имеют индивидуальные особенности в этом плане. Так, из-за особенностей расположения вторичного электронного умножителя в квадрупольном анализаторе для ионов с бо́льшими массами коэффициент усиления оказывается меньше, чем для более легких ионов;

- как правило, из практических соображений регистрируется не весь масс-спектр, и ионы с массами меньше чем $m / z=30$ а.е.м. отсекаются. Это означает, что два вещества с одинаковыми сечениями ионизации, попадающие в одинаковом количестве в камеру ионизации, при детектировании будут давать неодинаковую интенсивность суммарного ионного тока, и разница в интенсивности будет тем больше, чем больше различий в балансе самых легких и остальных ионов для двух этих веществ.

Как и при использовании других типов детекторов (см. выше), использование масс-селективного детектора для количественного анализа летучих веществ требует знаний о коэффициентах чувствительности

\footnotetext{
${ }^{10}$ англ.: Pulsed-Discharge Photo Ionisation Detector (PDPID).

${ }^{11}$ Современные времяпролетные масс-спектрометры позволяют регистрировать 100 и более полных масс-спектров в секунду.
} 
отдельных компонентов анализируемых смесей. Исследованы зависимости коэффициентов чувствительности масс-спектрометрического детектора от структуры молекул и показано, что масс-селективный детектор в целом менее чувствителен к н-алканам по сравнению с соответствующими галоген-производными, причем для полигалогеналканов наблюдались значительные отклонения от правила аддитивности [175].

\section{Стандарты и стандартные смеси}

Количественный анализ методом газовой хроматографии требует использования стандартов - то есть веществ известной чистоты или смесей известного состава для выполнения калибровки. В качестве стандарта можно использовать любое вещество, удовлетворяющее следующему набору условий [142, 144]: (1) сходство химической природы стандарта и анализируемых веществ для достижения полного смешения с пробой и обеспечения сопоставимых хроматографических характеристик стандарта и анализируемых компонентов, (2) стабильность при хранении и устойчивость в условиях анализа, (3) инертность по отношению ко всем компонентам анализируемой смеси, (4) известная, определенная независимым методом чистота и отсутствие примесей, пики которых перекрывались бы с пиками анализируемой смеси. Такой перечень требований не всегда позволяет легко подобрать стандарт для количественного анализа определенных смесей [176].

Анализ и определение чистоты таких калибровочных стандартов и смесей - самостоятельная и довольно сложная задача. Различные подходы к выполнению такого рода анализов описан в работах [177, 178]. Существуют различные подходы, позволяющие экономить время на приготовлении и анализе стандартных смесей [179]. В работе [180] описана процедура приготовления и использования стандартов с концентрациями порядка 1-10 нг/мкл для определения содержания моно- и сесквитерпеноидов в биологических жидкостях методом ГЖХ.

Множество веществ по разным причинам недоступны в качестве стандартов для количественного анализа, и в этих случаях неопределенность неизбежна. Однако этой неопределенности можно избежать и точно определить количество смеси, содержащей один или несколько недоступных компонентов с использованием группового корреляционного метода [181].

\section{Количественная спектроскопия ЯМР}

Количественная спектроскопия ЯМР ${ }^{12}$ в сравнении с хроматографическими методами является универсальным приемом обнаружения целевых компонентов в смесях любой сложности и дает возможность определить их количественное содержание [182]. В отношении анализа экстрактов растений количественный ЯМР демонстрирует очевидные преимущества перед традиционными методами, основанными на хроматографическом разделении [183]. Решающее преимущество заключается в том, что для количественных измерений с использованием ЯМР нет необходимости использовать чистый аутентичный стандарт определяемого вещества, а количественный анализ может быть выполнен с применением любого доступного чистого образца органического вещества, которое используется в качестве внутреннего стандарта [184]. Еще одной особенностью ЯМР является то, что количественные измерения можно выполнять одновременно для нескольких компонентов исследуемого образца [185] с использованием единственного стандарта [186]. Количественные измерения методом ЯМР можно выполнять в отсутствие вообще какого-либо стандарта при условии использования сигналов растворителя для расчета концентраций [186].

\section{Особенности анализа некоторых групп веществ}

Каждая группа летучих растительных метаболитов требует особого подхода к выбору метода и условий анализа с учетом специфических физических, физико-химических и химических свойств соединений. Применительно к анализу методом газовой хромато-масс-спектрометрии особенности анализа различных групп соединений описаны в руководстве [10, с. 172-180]. Поэтому здесь мы не будем повторяться, а дадим сведения, не вошедшие в упомянутую монографию или же появившиеся после ее опубликования.

\section{Нормальные углеводороды}

Нормальные углеводороды - часто встречающаяся группа соединений, извлекаемых из живых растений и растительного сырья и ископаемых источников. Смеси нормальных алканов являются непремен-

\footnotetext{
${ }^{12}$ англ.: quantitative Nuclear Magnetic Resonance - qNMR [87].
} 
ными компонентами эпикутикулярного воска растений [187]. Нормальные углеводороды используются как универсальные стандарты для расчетов индексов удерживания в газовой хроматографии и при калибровке колонок для гельпроникающей хроматографии с целью определения важных параметров при анализе нефтяных фракций [188]. Нормальные алканы содержатся во всех нефтепродуктах и горюче-смазочных материалах и поэтому часто попадают как загрязняющие примеси в растительные экстракты.

Анализ нефтей и нефтяных фракций имеет особое значение для хроматографического анализа, поскольку многие принципиальные вопросы качественного и количественного анализа хроматографическими методами были разработаны именно на примере анализа нефтяных фракций. На примере анализа нефтяных фракций разработаны любопытные подходы, связанные с симуляцией данных дистилляции для количественного анализа с использованием поправочных коэффициентов [189].

\section{Жирные кислоты и эфиры жирных кислот}

Жирные кислоты являются одними из основных промежуточных продуктов первичного метаболизма и, как правило, не накапливаются в растениях в свободном виде, а депонируются в виде триглицеридов (жиров) и используются в синтезе различных групп липидов [190]. Свободные жирные кислоты являются сигнальными веществами и участвуют, таким образом, в регуляции некоторых ферментативных процессов [191]. Свободные жирные кислоты содержатся в небольшом количестве в эпикутикулярном воске растений $[187,192]$.

Жирные кислоты обычно не анализируют как таковые, а превращают в метиловые эфиры, методы анализа которых хорошо разработаны и позволяют определять жирнокислотный состав продуктов различного происхождения [193]. Хроматографический анализ алкиловых эфиров жирных кислот в последнее время вновь привлекает внимание в связи с анализом биодизеля [194-196], который становится все более популярным видом топлива.

\section{Эфирные масла}

Хроматографические методы в области анализа состава эфирных масел - тема хорошо разработанная. В обзоре [70] рассматривается современное состояние методологической базы в части получения и анализа эфирных масел. Количественный анализ эфирного масла по-прежнему представляет серьезную проблему из-за сложности состава и недоступности большинства компонентов как аналитических стандартов. Специальным исследованием показано, что газовая хромато-масс-спектрометрия без использования поправок на коэффициенты чувствительности отдельных компонентов дает очень неточные сведения о содержании компонентов [197]. Последние достижения в области инструментального обеспечения в хроматографическом анализе эфирных масле обсуждается в обзорах [4-7].

Из-за изменчивости растений и влияния различных внешних факторов выходы и состав масла для одного и того же вида растений сильно различаются [198-200]. Получаемый состав эфирного масла для исследуемого вида растений и сравнение полученных данных с опубликованными в литературе сведениями может обескуражить. Несовпадение собственных и литературных данных связано, по крайней мере, с двумя обстоятельствами: уже упоминавшейся естественной изменчивости растений и различиями в технологи переработки и анализа, что влечет за собой образование разных наборов артефактов. В таких случаях может помочь сравнение со стандартными хроматографическими профилями для данного вида (хемотипа). К сожалению, стандартные хроматографические профили можно найти только для коммерчески доступных эфирных масел. Что касается дикорастущих растений, то единственная сводка существует для эфирномасличной флоры Южной Сибири [14].

\section{Гидропероксиды терпенов}

Как уже упоминалось выше, продукты, образующиеся за счет окисления терпенов при хранении эфирных масел, являются сильными аллергенами, а потому их содержание в различных терпенсодержащих продуктах требует особого контроля. Количественная оценка содержания терпеновых гидропероксидов представляет собой большую проблему, поскольку при использовании обычных хроматогарфических приемов для калибровки требуются стандартные образцы, которые имеют очень ограниченную доступность и из-за их химической нестабильности требуют особых условий хранения $\left(-78{ }^{\circ} \mathrm{C}\right)$. Для преодоления этих ограничений разработан подход, основанный на анализе методом GC-FID силилированных проивзодных гидропероксидов с прогнозированием факторов отклика [201]. Такая процедура обеспечивает хорошую альтернативу полной калибровке до уровня концентрации 500 мг/кг, хотя при анализе эфирных 
масел и искусственных ароматических смесей обнаруживаются большие отклонения, что связано не с погрешностями метода, а с лабильностью гидропероксидов, которые легко вступают в реакции с другими компонентами смесей. Ошибки в определении содержания гидропероксидов с использованием газовой хроматографии связаны помимо всего прочего с термолабильностью этих соединений, поскольку избежать нагрева в газохроматографическом эксперименте невозможно. Поэтому разработан простой и чувствительный метод с использованием тандемной жидкостной хромато-масс-спектрометрии (LC/ESI-MS/MS) для количественного определения гидропероксидов из линалоола, линилалацетата и лимонена [202].

\section{Ароматические вещества}

Поскольку эфирные масла и экстракты являются очень важными ингредиентами при производстве ароматических и вкусовых добавок, наметилась тенденция по ужесточению требований в части оборота природных продуктов, используемых для этих целей [203]. В этой связи разрабатываются новые подходы к быстрому анализу летучие соединения в различных ароматизаторах без использования аутентичных соединений в качестве стандартов, чтобы избежать трудоемких процедур калибровки [204].

Несмотря на повсеместное использование природных душистых и пряно-ароматичеких добавок, часто упускается из виду, что не все природные компоненты одинаково безобидны. Многие натуральные смеси, используемые для придания аромата и вкуса разнообразным продуктам, таят в себе природные вещества, содержание которых не должно превышать установленных норм из-за их токсического действия. Хотя известно об этом было уже давно, первая систематическая аналитическая работа на эту тему появилась только в 2015 году, когда рабочая группа по методам анализа Международной организации пряноароматической промышленности ${ }^{13}$ разработала метод быстрого рутинного количественного определения ряда веществ такого типа - $\beta$-азарона, кумарина, ментофурана, метилхавикола, метилэгенола, пулегона, сафрола и $\alpha$ - и $\beta$-туйонов - с помощью газовой хроматографии-масс-спектрометрии. Метод был опробован в разных лабораториях и показал хорошую эффективность [205].

\section{Сесквитерпеноиды}

Как уже отмечалось выше, сесквитерпеноиды являются очень сложным объектом анализа (см. выше раздел «Двумерные и гибридные методы»). Среди сесквитереновых соединений встречаются широко распространенные соединения, идентификация которых методами хромато-масс-спектрометрии обычно не вызывает проблем (кариофиллен/изокариофиллен, гумулен, лонгифолен, гермакрен D, окись кариофиллена, спатуленол, бизаболол и проч.). Вместе с тем подавляющее большинство сесквитерпеновых соединений бывает очень непросто идентифицировать из-за схожести индексов удерживания и масс-спектров. Именно по этой причине, во избежание ошибок идентификации, в правилах для авторов специализированного журнала Flavour and Fragrance Journal отмечается, что совпадение индексов удерживания и масс-спектров электронного удара не является достаточным основанием для идентификации необычных сесквитерпенов, а потому идентификацию требуется подтвердить дополнительными спектральными методами - ГЖХ-ИК и/или ЯМР.

Количественный анализ сесквитерпеновых соединений также представляет собой непростую задачу из-за недоступности подавляющего большинства соединений этой группы в виде аналитических стандартов.

Пример разработки и валидации аналитических методик количественного определения ключевых сесквитерпенов - $\beta$-кариофиллена, $\alpha$-копаена и $\alpha$-гумулена, содержащихся в препаратах из растений рода Copaifera (сем. Leguminosae = Fabaceae), с использованием 1,2,4,5-тетраметилбензола в качестве внутреннего стандарта описан в работе [206]. Многие важные в практическом отношении сесквитерпеноиды являются полифункциональными производными, которые нестабильны в условиях газовой хроматографии. Описаны подходы к количественному определению ключевых сесквитерпеновых производных (цезоарондола, изозодоарондола, аэугидиола, гермакрон-4,5-эпоксида, куркуменона, гермакрона, неокурдиона и фуранодиена), содержащихся в препаратах, изготовленных на основе куркумы (Curcuma ssp.), методом жидкостной хроматографии с исполььзованием единого стандарта - курдиона [207].

\footnotetext{
${ }^{13}$ англ.: International Organization of the Flavor Industry (IOFI).
} 


\section{Анализ биогенных летучих веществ в воздухе}

Летучие органические соединения играют важную роль в химии атмосферы и биогеохимии, поскольку биогенные выбросы обеспечивают наибольшую долю неметановых летучих органических соединений атмосферы. Среди аналитических методов их определения в атмосфере газовая хроматография в сочетании с масс-спектрометрией дает ряд преимуществ [208]. Однако для точной количественной калибровки необходима калибровка со стандартными веществами, которые далеко не всегда доступны. Особенностью анализов содержания монотерпенов в воздухе является необходимость использования стандартных смесей очень малой концентрации. В работе [209] описаны процедуры приготовления таких смесей с концентрацией порядка 2 нМ.

Для решения этой проблемы разработана модель количественного соотношения структура — свойство для прогнозирования коэффициентов отклика масс-селективного детектора для различных химических структур с использованием 7-параметровой модели [210]. Средняя ошибка в прогнозировании коэффициентов отклика была рассчитана с помощью процедуры перекрестной проверки и была ниже $20 \%$, что достаточно для определения летучих органических веществ в воздухе. Описан также метод количественных измерений летучих биогенных органических веществ в воздухе с использованием пламенноионизационного детектора в рамках концепции эффективного углеродного числа [211].

В некоторых случаях для осуществления непрерывного мониторинга биогенных органических веществ в воздухе требуется повышенное по сравнению с рутинными измерениями временное разрешение. В этой связи разработана новая полностью автоматизированная технология быстрой газовой хроматографии для обеспечения более высокого контроля временного разрешения монотерпенов и ряда других терпенов $\mathrm{C}_{9}-\mathrm{C}_{15}$ [71]. Показано, что за время анализа 10-20 мин можно достичь удовлетворительной точности измерений, характеризующихся погрешностью $\leq 12 \%$ при измерении концентраций монотрепеноидов и погрешностью 25\% при определении концентраций окисленных сесквитерпеноидов.

\section{Заключение}

Широкое распространение новейшего газохроматографического оборудования, оснащенного современными программными средствами сбора, первичной обработки и анализа экспериментальных данных, привело к тому, что значительная часть эксперимента — от ввода пробы и до получения данных об идентификации и количественному содержанию компонентов - осуществляется в автоматическом режиме, что превращает анализ летучих и условно летучих веществ растительных экстрактов в «легкую прогулку». При этом следует помнить, что видимая простота, свойственная рутинному анализу, касается чисто технической стороны дела. Современные аппаратные и программные средства и в самом деле существенно облегчают выполнение измерений, сводя к минимуму необходимость ручного труда. Однако надо понимать, что совершенствование техники эксперимента не меняет основ метода, а потому не устраняет принципиальных ограничений данного метода исследования. Поэтому хроматографические или хромато-массспектрометрические данные, получаемые в автоматическом режиме, должны быть подвергнуты беспристрастной ревизии со стороны экспериментатора с учетом всех известных ограничений, свойственных тому или иному хроматографическому методу разделения или детектирования компонентов, чтобы избежать ошибок при публикации результатов. Для правильной интерпретации получаемых данных необходимо знать всю историю анализируемого образца, а для этого все манипуляции с растительным материалом - от сбора сырья и до финальной пробоподготовки - должны быть самым тщательным образом задокументированы. Только в этом случае можно рассчитывать на получение значимых результатов исследования.

\section{Благодарности}

Автор благодарит руководителя Испьтательного аналитического центра при НИОХ СО РАН Сергея Владимировича Морозова за конструктивную критику и полезные замечания при подготовке рукописи.

\section{Список литературы}

1. Bohlmann J., Keeling C.I. Terpenoid biomaterials // The Plant Journal. 2008. Vol. 54, No. 4. Pp. 656-669. DOI: 10.1111/j.1365-313X.2008.03449.x

2. Schwab W., Davidovich-Rikanati R., Lewinsohn E. Biosynthesis of plant-derived flavor compounds // The Plant Journal. 2008. Vol. 54, No. 4. Pp. 712-732. DOI: 10.1111/j.1365-313X.2008.03446.x 
3. Морозов С.В., Ткачева Н.И., Ткачев А.В. Проблемы комплексного химического профилирования лекарственных растений // Фармация и фармакология. 2017. (в печати)

4. Bicchi C., Cagliero C., Rubiolo P. New trends in the analysis of the volatile fraction of matrices of vegetable origin: a short overview. A review // Flavour and Fragrance Journal. 2011. Vol. 26, No. 5. Pp. 321-325. DOI: 10.1002/ffj.2059

5. Sgorbini B., Cagliero C., Boggia L., Liberto E., Reichenbach S. E., Rubiolo P., Cordero C., Bicchi C. Parallel dual secondary-column-dual detection comprehensive two-dimensional gas chromatography: a flexible and reliable analytical tool for essential oils quantitative profiling // Flavour and Fragrance Journal. 2015. Vol. 30, No. 5. Pp. 366-380. DOI: 10.1002/ffj. 3255

6. Harman-Ware A.E., Sykes R., Peter G.F., Davis M. Determination of terpenoid content in pine by organic solvent extraction and fast-GC analysis // Frontiers in Energy Research. 2016. Vol. 4. Pp. 2. DOI: 10.3389/fenrg.2016.00002

7. Tranchida P.Q., Franchina F.A., Mondello L. Analysis of essential oils through comprehensive two-dimensional gas chromatography: General utility // Flavour and Fragrance Journal. 2017. Vol. 32, No. 4. Pp. 218-227. DOI: 10.1002/ffj.3383

8. Middleditch B.S. Analytical Artifacts: GC, MS, HPLC, TLC and PC. J. of Chromatography Library, Vol. 44 Elsevier Science Ltd. 1989. 1033 p.

9. Jones, W.P., Kinghorn, A.D. Extraction of plant secondary metabolites // Natural Products Isolation. Humana Press. 2005. Pp. 323-351. DOI: 10.1385/1-59259-955-9:323

10. Ткачев А.В. Исследование летучих веществ растений. Новосибирск, 2008. 969 с.

11. Huopalahti R., Kesälahti E. Effect of drying and freeze-drying on the aroma of Dill - Anethum graveolens CV Mammut // Essential Oils and Aromatic Plants: Proceedings of the 15th International Symposium on Essential Oils, held in Noordwijkerhout, The Netherlands, July 19-21, 1984. Springer Netherlands. 1985. Pp. 179-184. DOI: 10.1007/978-94009-5137-2_19

12. Ткачев А.В., Королюк Е.А., Юсубов М.С., Гурьев А.М. Изменение состава эфирного масла при разных сроках хранения сырья // Химия растительного сырья. 2002. №. 1. С. 19-30.

13. Utsumi S.A., Cibils A.F., Estell R.E., Wang Y.-F. Influence of plant material handling protocols on terpenoid profiles of one-seed Juniper saplings // Rangeland Ecology, Management. 2006. Vol. 59, No. 6. Pp. 668-673. DOI: 10.2111/06010R1.1

14. Ткачев А.В., Прокушева Д.Л., Домрачев Д.В. Дикорастущие эфирномасличные растения Южной Сибири. Новосибирск, 2017. $575 \mathrm{c}$.

15. Kubeczka K.-H. Progress in isolation techniques for essential oil constituents // Essential Oils and Aromatic Plants: Proceedings of the 15th International Symposium on Essential Oils, held in Noordwijkerhout, The Netherlands. July 19-21. 1984. Springer Netherlands. 1985. Pp. 107-126. DOI: 10.1007/978-94-009-5137-2_9

16. Casteel D.A. Peroxy natural products // Natural Product Reports. 1992. Vol. 9, No. 4. Pp. 289-312. DOI: 10.1039/NP9920900289

17. Casteel D. A. Peroxy natural products // Natural Product Reports. 1999. Vol. 16, No. 1. Pp. 55-73. DOI: 10.1039/A705725C

18. Jung M., Kim H., Lee K., Park M. Naturally occurring peroxides with biological activities // Mini Reviews in Medicinal Chemistry. 2003. Vol. 3, No. 2. Pp. 159-165. DOI: 10.2174/1389557033405313

19. Liu D.-Z., Liu J.-K. Peroxy natural products // Natural Products and Bioprospecting. 2013. Vol. 3, No. 5. Pp. $161-206$. DOI: $10.1007 / \mathrm{s} 13659-013-0042-7$

20. Bu M., Yang B.B., Hu L. Natural endoperoxides as drug lead compounds // Current medicinal chemistry. 2016. Vol. 23, No. 4. Pp. 383-405. DOI: 10.2174/0929867323666151127200949

21. Wolfenden R., Lu X., Young G. Spontaneous hydrolysis of glycosides // Journal of the American Chemical Society. 1998. Vol. 120, No. 27. Pp. 6814-6815. DOI: 10.1021/ja9813055

22. Zhang W. L., Chen J.-P., Lam K. Y.-C., Zhan J. Y.-X., Yao P., Dong T. T.-X., Tsim K. W.-K. Hydrolysis of glycosidic flavonoids during the preparation of Danggui Buxue Tang: an outcome of moderate boiling of chinese herbal mixture // Evidence-Based Complementary and Alternative Medicine. 2014. Vol. 2014. DOI: 10.1155/2014/608721

23. Bolarinwa I.F., Oke M.O., Olaniyan S.A., Ajala A.S. A review of cyanogenic glycosides in edible plants // Toxicology New Aspects to This Scientific Conundrum. InTech. 2016. Pp. 179-191. DOI: 10.5772/64886

24. Schmaus G., Kubeczka K.-H. The influence of isolation conditions on the composition of essential oils containing linalool and linalyl acetate // Essential Oils and Aromatic Plants: Proceedings of the 15th International Symposium on Essential Oils, held in Noordwijkerhout, The Netherlands. July 19-21. 1984. Springer Netherlands. 1985. Pp. 127-134. DOI: 10.1007/978-94-009-5137-2_10

25. Baldermann S., Yang Z., Sakai M., Fleischmann P., Watanabe N. Volatile constituents in the scent of roses // Floriculture and Ornamental Biotechnology. 2009. Vol. 3, No. 1. Pp. 89-97.

26. Jean F.-I., Garneau F.-X., Collin G. J., Bouhajib M., Zamir L. O. The essential oil and glycosidically bound volatile compounds of Taxus canadensis Marsh // Journal of Essential Oil Research. 1993. Vol. 5, No. 1. Pp. 7-11. DOI: 10.1080/10412905.1993.9698163

27. Mastelić J., Miloš M., Kuštrak D., Radonić A. The essential oil and glycosidically bound volatile compounds of Calamintha nepeta (L.) Savi // Croatica Chemica Acta. 1998. Vol. 71, No. 1. Pp. 147-154. URL: http://hrcak.srce.hr/132332

28. Mastelić J., Miloš M., Kuštrak D., Radonić A. Essential oil and glycosidically bound volatile compounds from the needles of common Juniper (Juniperus communis L.) // Croatica Chemica Acta. 2000. Vol. 73, No. 2. Pp. $585-593$. URL: http://hrcak.srce.hr/132073 
29. Politeo O., Jukic M., Milos M. Comparison of chemical composition and antioxidant activity of glycosidically bound and free volatiles from Clove (Eugenia caryophyllata Thunb.) // Journal of Food Biochemistry. 2010. Vol. 34, No. 1. Pp. 129141. DOI: $10.1111 / \mathrm{j} .1745-4514.2009 .00269 . \mathrm{x}$

30. Sgorbini B., Cagliero C., Pagani A., Sganzerla M., Boggia L., Bicchi C., Rubiolo P. Determination of free and glucosidically-bound volatiles in plants. Two case studies: L-menthol in peppermint (Mentha x piperita L.) and eugenol in clove (Syzygium aromaticum (L.) Merr., L.M.Perry) // Phytochemistry. 2015. Vol. 117. Pp. 296-305. DOI: 10.1016/j.phytochem.2015.06.017

31. Tissier A. Glandular trichomes: what comes after expressed sequence tags? // The Plant Journal. 2012. Vol. 70 , No. 1. Pp. 51-68. DOI: 10.1111/j.1365-313X.2012.04913.x

32. Lange M.B., Turner G.W. Terpenoid biosynthesis in trichomes - current status and future opportunities // Plant Biotechnology Journal. 2013. Vol. 11, No. 1. Pp. 2-22. DOI: 10.1111/j.1467-7652.2012.00737.x

33. Schilmiller A. L., Last R. L., Pichersky E. Harnessing plant trichome biochemistry for the production of useful compounds // The Plant Journal. 2008. Vol. 54, No. 4. Pp. 702-711. DOI: 10.1111/j.1365-313X.2008.03432.x

34. Bicchi C., D' Amato A., Frattini C., Nano G.M., Cappelletti E., Caniato R. Analysis of essential oils by direct sampling from plant secretory structures and capillary gas chromatography // Journal of High Resolution Chromatography. 1985. Vol. 8, No. 8. Pp. 431-435. DOI: 10.1002/jhrc.1240080815

35. Fischer N., Nitz S., Drawert F. Original flavour compounds and the essential oil composition of Marjoram (Majorana hortensis Moench) // Flavour and Fragrance Journal. 1987. Vol. 2, No. 2. Pp. 55-61. DOI: 10.1002/ffj.2730020204

36. Toyota M., Koyama H., Mizutani M., Asakawa Y. (-)-ent-Spathulenol isolated from liverworts is an artefact // Phytochemistry. 1996. Vol. 41, No. 5. Pp. 1347-1350. DOI: 10.1016/0031-9422(95)00798-9

37. Holloway P.J. The chemical constitution of plant cutins // The plant cuticle. Academic Press, London New York. 1982. Pp. 45-84.

38. Boom A., Damsté J. S., de Leeuw J. Cutan, a common aliphatic biopolymer in cuticles of drought-adapted plants // Organic Geochemistry. 2005. Vol. 36, No. 4. Pp. 595-601. DOI: 10.1016/j.orggeochem.2004.10.017

39. Valkama E., Salminen J.-P., Koricheva J., Pihlaja K. Comparative analysis of leaf trichome structure and composition of epicuticular flavonoids in Finnish Birch species // Annals of Botany. 2003. Vol. 91, No. 6. Pp. 643-655. DOI: $10.1093 / \mathrm{aob} / \mathrm{mcg} 070$

40. Guhling O., Kinzler C., Dreyer M., Bringmann G., Jetter R. Surface composition of myrmecophilic plants: Cuticular wax and glandular trichomes on leaves of Macaranga tanarius // Journal of Chemical Ecology. 2005. Vol. 31, No. 10. Pp. 2323-2341. DOI: 10.1007/s10886-005-7104-1

41. Can Baser K.H., Buchbauer G. Handbook of Essential Oils: Science, Technology, and Applications. Second Edition. CRC Press. 2016. 1095 p.

42. Matura M., Sköld M., Börje A., Andersen K. E., Bruze M., Frosch P., Goossens A., Johansen J. D., Svedman C., White I. R., Karlberg A.-t. Selected oxidized fragrance terpenes are common contact allergens // Contact Dermatitis. 2005. Vol. 52, No. 6. Pp. 320-328. DOI: 10.1111/j.0105-1873.2005.00605.x

43. Christensson J.B., Matura M., Gruvberger B., Bruze M., Karlberg A.-T. Linalool - a significant contact sensitizer after air exposure // Contact Dermatitis. 2010. Vol. 62, No. 1. Pp. 32-41. DOI: 10.1111/j.1600-0536.2009.01657.x

44. Bråred Christensson J., Andersen K. E., Bruze M., Johansen J. D., Garcia-Bravo B., Gimenez Arnau A., Goh C.-L., Nixon R., White I. R. Air-oxidized linalool - a frequent cause of fragrance contact allergy // Contact Dermatitis. 2012. Vol. 67, No. 5. Pp. 247-259. DOI: 10.1111/j.1600-0536.2012.02134.x

45. Bråred Christensson J., Karlberg A.-T., Andersen K.E., Bruze M., Johansen J.D., Garcia-Bravo B., Giménez Arnau A. Goh C.-L., Nixon R., White I.R. Oxidized limonene and oxidized linalool - concomitant contact allergy to common fragrance terpenes // Contact Dermatitis. 2016. Vol. 74, No. 5. Pp. 273-280. DOI: 10.1111/cod.12545

46. Sköld M., Hagvall L., Karlberg A.-T. Autoxidation of linalyl acetate, the main component of lavender oil, creates potent contact allergens // Contact Dermatitis. 2008. Vol. 58, No. 1. Pp. 9-14. DOI: 10.1111/j.1600-0536.2007.01262.x

47. Hagvall L., Berglund V., Bråred Christensson J. Air-oxidized linalyl acetate - an emerging fragrance allergen? // Contact Dermatitis. 2015. Vol. 72, No. 4. Pp. 216-223. DOI: 10.1111/cod.12350

48. Matura M., Goossens A., Bordalo O., Garcia-Bravo B., Magnusson K., Wrangsjö K., Karlberg A.-T. Patch testing with oxidized R-(+)-limonene and its hydroperoxide fraction // Contact Dermatitis. 2003. Vol. 49, No. 1. Pp. 15-21. DOI: 10.1111/j.0105-1873.2003.00135.x

49. Matura M., Sköld M., Börje A., Andersen K.E., Bruze M., Frosch P., Goossens A., Johansen J.D., Svedman C., White I.R., Karlberg A.-T. Not only oxidized R-(+)- but also S-(-)-limonene is a common cause of contact allergy in dermatitis patients in Europe // Contact Dermatitis. 2006. Vol. 55, No. 5. Pp. 274-279. DOI: 10.1111/j.1600-0536.2006.00939.x

50. Christensson J.B., Johansson S., Hagvall L., Jonsson C., Börje A., Karlberg A.-T. Limonene hydroperoxide analogues differ in allergenic activity // Contact Dermatitis. 2008. Vol. 59, No. 6. Pp. 344-352. DOI: 10.1111/j.1600-0536.2008.01442.x

51. Bråred Christensson J., Andersen K. E., Bruze M., Johansen J. D., Garcia-Bravo B., Giménez-Arnau A., Goh C.-L., Nixon R., White I. R. An international multicentre study on the allergenic activity of air-oxidized R-limonene // Contact Dermatitis. 2013. Vol. 68, No. 4. Pp. 214-223. DOI: 10.1111/cod.12036

52. Bråred Christensson J., Hellsén S., Börje A., Karlberg A.-T. Limonene hydroperoxide analogues show specific patch test reactions // Contact Dermatitis. 2014. Vol. 70, No. 5. Pp. 291-299. DOI: 10.1111/cod.12195

53. Niklasson I.B., Delaine T., Islam M.N., Karlsson R., Luthman K., Karlberg A.-T. Cinnamyl alcohol oxidizes rapidly upon air exposure // Contact Dermatitis. 2013. Vol. 68, No. 3. Pp. 129-138. DOI: 10.1111/cod.12009 
54. Rudbäck J., Hagvall L., Börje A., Nilsson U., Karlberg A.-T. Characterization of skin sensitizers from autoxidized citronellol-impact of the terpene structure on the autoxidation process // Contact Dermatitis. 2014. Vol. 70, No. 6. Pp. 329-339. DOI: $10.1111 /$ cod.12234

55. Hagvall L., Sköld M., Bråred-Christensson J., Börje A., Karlberg A.-T. Lavender oil lacks natural protection against autoxidation, forming strong contact allergens on air exposure // Contact Dermatitis. 2008. Vol. 59, No. 3. Pp. 143-150. DOI: 10.1111/j.1600-0536.2008.01402.x

56. Njoroge S.M., Ukeda H., Sawamura M. Changes in the volatile composition of Yuzu (Citrus junos Tanaka) cold-pressed oil during storage // Journal of Agricultural and Food Chemistry. 1996. Vol. 44, No. 2. Pp. 550-556. DOI: $10.1021 / \mathrm{j} 950284 \mathrm{k}$

57. Njoroge S.M., Ukeda H., Sawamura M. Changes of the volatile profile and artifact formation in Daidai (Citrus aurantium) cold-pressed peel oil on storage // Journal of Agricultural and Food Chemistry. 2003. Vol. 51, No. 14. Pp. 4029-4035. DOI: $10.1021 / \mathrm{jf0} 21215 \mathrm{q}$

58. Sun H., Ni H., Yang Y., Wu L., Cai H.-n., Xiao A.-f., Chen F. Investigation of sunlight-induced deterioration of aroma of Pummelo (Citrus maxima) essential oil // Journal of Agricultural and Food Chemistry. 2014. Vol. 62, No. 49. Pp. 1181811830. DOI: $10.1021 / \mathrm{jf504294g}$

59. Turek C., Stintzing F.C. Evaluation of selected quality parameters to monitor essential oil alteration during storage // Journal of Food Science. 2011. Vol. 76, No. 9. Pp. C1365-C1375. DOI: 10.1111/j.1750-3841.2011.02416.x

60. Turek C., Stintzing F. C. Stability of essential oils: a review // Comprehensive Reviews in Food Science and Food Safety. 2013. Vol. 12, No. 1. Pp. 40-53. DOI: 10.1111/1541-4337.12006

61. Kashiwagi T., Lan Phi N.T., Sawamura M. Compositional changes in Yuzu (Citrus junos) steam-distilled oil and effects of antioxidants on oil quality during storage // Food Science and Technology Research. 2010. Vol. 16, No. 1. Pp. 51-58. DOI: $10.3136 /$ fstr.16.51

62. Takeda K., Horibe I., Minato H. Absolute configuration of bicycloelemene and conformation of bicyclogermacrene // J. Chem. Soc. D. 1971. No. 7. Pp. 308. DOI: 10.1039/C29710000308

63. Reichardt P.B., Anderson B.J., Clausen T.P., Hoskins L.C. Thermal instability of germacrone: implications for gas chromatographic analysis of thermally unstable analytes // Canadian Journal of Chemistry. 1989. Vol. 67, No. 7. Pp. 1174-1177. DOI: $10.1139 / \mathrm{v} 89-177$

64. Garcia G., Charmillon J.-M., Roux E., Sutour S., Rakotozafy J. B., Désiré O., Paoli M., Tomi F., Rabehaja D. J. R. Chemical composition of leaf and bark essential oils of Vepris unifoliolata from Madagascar // Journal of Essential Oil Research. 2017. Vol. 29, No. 3. Pp. 214-220. DOI: 10.1080/10412905.2016.1251982

65. Rabe P., Barra L., Rinkel J., Riclea R., Citron C.A., Klapschinski T.A., Janusko A., Dickschat J.S. Conformational analysis, thermal rearrangement, and EI-MS fragmentation mechanism of $(1(10) \mathrm{E}, 4 \mathrm{E}, 6 \mathrm{~S}, 7 \mathrm{R})$-germacradien-6-ol by ${ }^{13} \mathrm{C}-$ labeling experiments // Angewandte Chemie International Edition. 2015. Vol. 54, No. 45. Pp. 13448-13451. DOI: 10.1002/anie.201507615

66. Nilsson J., Carlberg J., Abrahamsson P., Hulthe G., Persson B.-A., Karlberg A.-T. Evaluation of ionization techniques for mass spectrometric detection of contact allergenic hydroperoxides formed by autoxidation of fragrance terpenes // Rapid Communications in Mass Spectrometry. 2008. Vol. 22, No. 22. Pp. 3593-3598. DOI: 10.1002/rcm.3770

67. Valcárcel M., Cárdenas S., Simonet B., Carrillo-Carrión C. Principles of qualitative analysis in the chromatographic context // Journal of Chromatography A. 2007. Vol. 1158, No. 1-2. Pp. 234-240. DOI: 10.1016/j.chroma.2007.03.034

68. Stashenko E.E., Martínez J.R. GC-MS analysis of volatile plant secondary metabolites // Gas Chromatography in Plant Science, Wine Technology, Toxicology and Some Specific Applications. InTech. 2012. Pp. 247-270. DOI: 10.5772/32246

69. Chamorro E.R., Zambón S.N., Morales W.G., Sequeira A. F., Velasco G.A. Study of the chemical composition of essential oils by gas chromatography // Gas Chromatography in Plant Science, Wine Technology, Toxicology and Some Specific Applications. InTech. 2012. Pp. 307-324. DOI: 10.5772/33201

70. Rubiolo P., Sgorbini B., Liberto E., Cordero C., Bicchi C. Essential oils and volatiles: sample preparation and analysis. A review // Flavour and Fragrance Journal. 2010. Vol. 25, No. 5. Pp. 282-290. DOI: 10.1002/ffj.1984

71. Jones C.E., Kato S., Nakashima Y., Kajii Y. A novel fast gas chromatography method for higher time resolution measurements of speciated monoterpenes in air // Atmospheric Measurement Techniques. 2014. Vol. 7, No. 5. Pp. $1259-1275$. DOI: $10.5194 / \mathrm{amt}-7-1259-2014$

72. Kováts E. Gas-chromatographische Charakterisierung organischer Verbindungen. Teil 1: Retentionsindices aliphatischer Halogenide, Alkohole, Aldehyde und Ketone // Helvetica Chimica Acta. 1958. Vol. 41, No. 7. Pp. 1915-1932. DOI: 10.1002/hlca. 19580410703

73. Wick C.D., Siepmann J., Klotz W. L., Schure M.R. Temperature effects on the retention of n-alkanes and arenes in heliumsqualane gas-liquid chromatography // Journal of Chromatography A. 2002. Vol. 954, No. 1. Pp. 181-190. DOI: $10.1016 /$ S0021-9673(02)00171-1

74. Héberger K. Quantitative structure-(chromatographic) retention relationships // Journal of Chromatography A. 2007. Vol. 1158, No. 1-2. Pp. 273-305. DOI: 10.1016/j.chroma. 2007.03.108

75. van den Dool H., Kratz P. D. A generalization of the retention index system including linear temperature programmed gasliquid partition chromatography // Journal of Chromatography. 1963. Vol. 11. Pp. 463-471. DOI: 10.1016/S00219673(01)80947-X

76. Bicchi C., Binello A., D'Amato A., Rubiolo P. Reliability of Van den Dool retention indices in the analysis of essential oils // Journal of Chromatographic Science. 1999. Vol. 37, No. 8. Pp. 288-294. DOI: 10.1093/chromsci/37.8.288 
77. Analytical Methods Committee Application of Gas-Liquid Chromatography to the Analysis of Essential Oils. Part XVII. Fingerprinting of Essential Oils by Temperature-programmed Gas-Liquid Chromatography Using Capillary Columns With Non-polar Stationary Phases // Analyst. 1997. Vol. 122. Pp. 1167-1174. DOI: 10.1039/A704651K

78. Adams R.P. Identification of Essential Oil Components by Gas Chromatography/Mass Spectroscopy, 4th Edition.. Allured Publishing Corporation, Illinois, USA. 2007. 804 p.

79. Gonzalez F., Nardillo A. Retention index in temperature-programmed gas chromatography // Journal of Chromatography A. 1999. Vol. 842, No. 1. Pp. 29-49. DOI: 10.1016/S0021-9673(99)00158-2

80. Ong R., Shellie R., Marriott P. Observation of non-linear chromatographic peaks in comprehensive two-dimensional gas chromatography // Journal of Separation Science. 2001. Vol. 24, No. 5. Pp. 367-377. DOI: 10.1002/16159314(20010501)24:5<367::AID-JSSC367>3.0.CO;2-U

81. Western R.J., Marriott P.J. Retention correlation maps in comprehensive two-dimensional gas chromatography // Journal of Separation Science. 2002. Vol. 25, No. 13. Pp. 831-838. DOI: 10.1002/1615-9314(20020901)25:13<831::AIDJSSC832>3.0.CO;2-R

82. Зенкевич И.Г. Новые методы расчета газохроматографических методов удерживания. Применение линейнологарифмических корреляционных уравнений, принципов структурной аналогии и методов молекулярной динамики // 100 лет хроматографии / под ред. Б.А. Руденко. М., 2003. С. 311-336.

83. Egolf L.M., Jurs P.C. Quantitative structure-retention and structure-odor intensity relationships for a diverse group of odoractive compounds // Analytical Chemistry. 1993. Vol. 65, No. 21. Pp. 3119-3126. DOI: 10.1021/ac00069a027

84. Kaliszan R., Bączek T. QSAR in chromatography: quantitative structure - retention relationships (QSRRs) // Recent Advances in QSAR Studies: Methods and Applications. Springer Netherlands. 2010. Pp. 223-259. DOI: 10.1007/978-1-40209783-6 8

85. Todeschini R., Consonni V. Handbook of Molecular Descriptors. WILEY-VCH Verlag GmbH. 2000. 667 p.

86. Beteringhe A., Radutiu A.C., Culita D.C., Mischie A., Spafiu F. Quantitative structure-retention relationship (QSRR) study for predicting gas chromatographic retention times for some stationary phases // QSAR, Combinatorial Science. 2008. Vol. 27, No. 8. Pp. 996-1005. DOI: 10.1002/qsar.200730097

87. Ausloos P., Clifton C., Lias S., Mikaya A., Stein S., Tchekhovskoi D., Sparkman O., Zaikin V., Zhu D. The critical evaluation of a comprehensive mass spectral library // Journal of the American Society for Mass Spectrometry. 1999. Vol. 10, No. 4. Pp. 287-299. DOI: 10.1016/S1044-0305(98)00159-7

88. Лебедев А.Т. Масс-спектрометрия в органической химии. М., 2003. 493 с.

89. McAndrew B.A. Sesquiterpenoids: the lost dimension of perfumery // Perfumer, Flavorist. 1992. Vol. 17, No. 4. Pp. 1-12.

90. Helmig D., Revermann T., Pollmann J., Kaltschmidt O., Hernández A.J., Bocquet F., David D. Calibration system and analytical considerations for quantitative sesquiterpene measurements in air // Journal of Chromatography A. 2003. Vol. 1002, No. 1-2. Pp. 193-211. DOI: 10.1016/S0021-9673(03)00619-8

91. Jacobsson U., Muddathir A. K. Four biologically active sesquiterpenes of the drimane type isolated from Polygonum glabrum // Phytochemistry. 1992. Vol. 31, No. 12. Pp. 4207-4211. DOI: 10.1016/0031-9422(92)80444-J

92. Zheng G.-Q., Kenney P.M., Lam L.K.T. Sesquiterpenes from Clove (Eugenia caryophyllata) as potential anticarcinogenic agents // Journal of Natural Products. 1992. Vol. 55, No. 7. Pp. 999-1003. DOI: 10.1021/np50085a029

93. Sabulal B., Dan M., Anil John J., Kurup R., Pradeep N.S., Valsamma R.K., George V. Caryophyllene-rich rhizome oil of Zingiber nimmonii from South India: Chemical characterization and antimicrobial activity // Phytochemistry. 2006. Vol. 67, No. 22. Pp. 2469-2473. DOI: 10.1016/j.phytochem.2006.08.003

94. Medeiros R., Passos G.F., Vitor C.E., Koepp J., Mazzuco T.L., Pianowski L.F., Campos M.M., Calixto J.B. Effect of two active compounds obtained from the essential oil of Cordia verbenacea on the acute inflammatory responses elicited by LPS in the rat paw // British Journal of Pharmacology. 2007. Vol. 151, No. 5. Pp. 618-627. DOI: 10.1038/sj.bjp.0707270

95. Gertsch J., Leonti M., Raduner S., Racz I., Chen J.-Z., Xie X.-Q., Altmann K.-H., Karsak M., Zimmer A. Betacaryophyllene is a dietary cannabinoid // Proceedings of the National Academy of Sciences. 2008. Vol. 105, No. 26. Pp. 9099-9104. DOI: 10.1073/pnas.0803601105

96. Langhasova L., Hanusova V., Rezek J., Stohanslova B., Ambroz M., Kralova V., Vanek T., Lou J.D., Yun Z.L., Yang J., Skalova L. Essential oil from Myrica rubra leaves inhibits cancer cell proliferation and induces apoptosis in several human intestinal lines // Industrial Crops and Products. 2014. Vol. 59. Pp. 20-26. DOI: 10.1016/j.indcrop.2014.04.018

97. Klauke A.-L., Racz I., Pradier B., Markert A., Zimmer A., Gertsch J., Zimmer A. The cannabinoid CB2 receptor-selective phytocannabinoid beta-caryophyllene exerts analgesic effects in mouse models of inflammatory and neuropathic pain // European Neuropsychopharmacology. 2014. Vol. 24, No. 4. Pp. 608-620. DOI: 10.1016/j.euroneuro.2013.10.008

98. Gubiani J.R., Zeraik M.L., Oliveira C.M., Ximenes V.F., Nogueira C.R., Fonseca L.M., Silva D.H.S., Bolzani V.S., Araujo A.R. Biologically active eremophilane-type sesquiterpenes from Camarops sp., an endophytic fungus isolated from Alibertia macrophylla // Journal of Natural Products. 2014. Vol. 77, No. 3. Pp. 668-672. DOI: 10.1021/np400825s

99. Sarpietro M.G., Sotto A.D., Accolla M.L., Castelli F. Interaction of $\beta$-caryophyllene and $\beta$-caryophyllene oxide with phospholipid bilayers: Differential scanning calorimetry study // Thermochimica Acta. 2015. Vol. 600. Pp. 28-34. DOI: $10.1016 /$ j.tca.2014.11.029

100. Fidyt K., Fiedorowicz A., Strządała L., Szumny A. $\beta$-caryophyllene and $\beta$-caryophyllene oxide - natural compounds of anticancer and analgesic properties // Cancer Medicine. 2016. Vol. 5, No. 10. Pp. 3007-3017. DOI: 10.1002/cam4.816

101. Joulain D., König W.A. Atlas of Spectral Data of Sesquiterpene Hydrocarbons. EB-Verlag. 2001. 658 p.

102. Lemberkovics É., Verzár-Petri, G. Gas chromatographic characterization of frequently occurring sesqui-terpenes in essential oils // Essential Oils and Aromatic Plants: Proceedings of the 15th International Symposium on Essential Oils, held in 
Noordwijkerhout, The Netherlands, July 19-21, 1984. Springer Netherlands. 1985. Pp. 103-105. DOI: 10.1007/978-94$009-5137-2$ \&

103. Sarker S.D., Nahar L. Hyphenated techniques // Natural Products Isolation. Humana Press. 2005. Pp. $233-267$. DOI: $10.1385 / 1-59259-955-9: 233$

104. Hubert J., Nuzillard J.-M., Renault J.-H. Dereplication strategies in natural product research: How many tools and methodologies behind the same concept? // Phytochemistry Reviews. 2017. Vol. 16, No. 1. Pp. 55-95. DOI: 10.1007/s11101015-9448-7

105. Marriott P.J., Massil T., Hügel H. Molecular structure retention relationships in comprehensive two-dimensional gas chromatography // Journal of Separation Science. 2004. Vol. 27, No. 15-16. Pp. 1273-1284. DOI: 10.1002/jssc.200401917

106. Pang T., Zhu S., Lu X., Xu G. Identification of unknown compounds on the basis of retention index data in comprehensive two-dimensional gas chromatography // Journal of Separation Science. 2007. Vol. 30, No. 6. Pp. 868-874. DOI: $10.1002 /$ jssc.200600471

107. Shellie R., Marriott P., Cornwell C. Application of comprehensive two-dimensional gas chromatography (GC $\times \mathrm{GC})$ to the enantioselective analysis of essential oils // Journal of Separation Science. 2001. Vol. 24, No. 10-11. Pp. 823-830. DOI: 10.1002/1615-9314(20011101)24:10/11<823::AID-JSSC823>3.0.CO;2-H

108. Cagliero C., Sgorbini B., Cordero C., Liberto E., Rubiolo P., Bicchi C. Enantioselective gas chromatography with derivatized cyclodextrins in the flavour and fragrance field // Israel Journal of Chemistry. 2016. Vol. 56, No. 11-12. Pp. 925-939. DOI: 10.1002/ijch.201600091

109. Tkachev A.V. Chirospecific analysis of plant volatiles // Russian Chemical Reviews. 2007. Vol. 76, No. 10. Pp. $951-969$. DOI: $10.1070 / \mathrm{RC} 2007 \mathrm{v} 076 \mathrm{n} 10 \mathrm{ABEH} 003728$

110. de Juan A., Tauler R. Factor analysis of hyphenated chromatographic data: Exploration, resolution and quantification of multicomponent systems // Journal of Chromatography A. 2007. Vol. 1158, No. 1-2. Pp. 184-195. DOI: 10.1016/j.chroma.2007.05.045

111. Baldovini N., Tomi F., Casanova J. Identification and quantitative determination of furanodiene, a heat-sensitive compound, in essential oil by ${ }^{13} \mathrm{C}-\mathrm{NMR} / /$ Phytochemical Analysis. 2001. Vol. 12, No. 1. Pp. 58-63. DOI: 10.1002/10991565(200101/02)12:1<58::AID-PCA559>3.0.CO;2-9

112. Cavalli J.-F., Tomi F., Bernardini A.-F., Casanova J. Combined analysis of the essential oil of Chenopodium ambrosioides by GC, GC-MS and ${ }^{13} \mathrm{C}-\mathrm{NMR}$ spectroscopy: quantitative determination of ascaridole, a heat-sensitive compound // Phytochemical Analysis. 2004. Vol. 15, No. 5. Pp. 275-279. DOI: 10.1002/pca.761

113. Blanc M.-C., Bradesi P., Casanova J. Identification and quantitative determination of eudesmane-type acids from the essential oil of Dittrichia viscosa sp. viscosa using ${ }^{13}$ C-NMR spectroscopy // Phytochemical Analysis. 2005. Vol. 16, No. 3. Pp. 150-154. DOI: 10.1002/pca.834

114. Duquesnoy E., Castola V., Casanova J. Triterpenes in the hexane extract of leaves of Olea europaea L.: analysis using ${ }^{13} \mathrm{C}$ NMR spectroscopy // Phytochemical Analysis. 2007. Vol. 18, No. 4. Pp. 347-353. DOI: 10.1002/pca.989

115. Ferrari B., Castilho P., Tomi F., Rodrigues A. I., do Ceu Costa M., Casanova J. Direct identification and quantitative determination of costunolide and dehydrocostuslactone in the fixed oil of Laurus novocanariensis by ${ }^{13} \mathrm{C}-\mathrm{NMR}$ spectroscopy // Phytochemical Analysis. 2005. Vol. 16, No. 2. Pp. 104-107. DOI: 10.1002/pca.825

116. Duquesnoy E., Paoli M., Castola V., Bighelli A., Casanova J. Identification of taxanes in extracts from leaves of Taxus baccata L. using ${ }^{13} \mathrm{C}-\mathrm{NMR}$ spectroscopy // Phytochemical Analysis. 2009. Vol. 20, No. 3. Pp. 246-252. DOI: 10.1002/pca.1121

117. Ratcliffe R. G., Roscher A., Shachar-Hill Y. Plant NMR spectroscopy // Progress in Nuclear Magnetic Resonance Spectroscopy. 2001. Vol. 39, No. 4. Pp. 267-300. DOI: 10.1016/S0079-6565(01)00035-8

118. Lerche M.H., Jensen P.R., Karlsson M., Meier S. NMR insights into the inner workings of living cells // Analytical Chemistry. 2015. Vol. 87, No. 1. Pp. 119-132. DOI: 10.1021/ac501467x

119. Krishnan P., Kruger N.J., Ratcliffe R.G. Metabolite fingerprinting and profiling in plants using NMR // Journal of Experimental Botany. 2005. Vol. 56, No. 410. Pp. 255-265. DOI: 10.1093/jxb/eri010

120. Kim H.K., Choi Y.H., Verpoorte R. NMR-based metabolomic analysis of plants // Nature Protocols. 2010. Vol. 5. Pp. 536549. DOI: 10.1038 /nprot.2009.237

121. Bligny R., Douce R. NMR and plant metabolism // Current Opinion in Plant Biology. 2001. Vol. 4, No. 3. Pp. $191-196$. DOI: $10.1016 / \mathrm{S} 1369-5266(00) 00160-6$

122. Eisenreich W., Bacher A. Advances of high-resolution NMR techniques in the structural and metabolic analysis of plant biochemistry // Phytochemistry. 2007. Vol. 68, No. 22. Pp. 2799-2815. DOI: 10.1016/j.phytochem.2007.09.028

123. Ristorcelli D., Tomi F., Casanova J. ${ }^{13} \mathrm{C}-\mathrm{NMR}$ as a tool for identification and enantiomeric differentiation of major terpenes exemplified by the essential oil of Lavandula stoechas L. ssp. stoechas // Flavour and Fragrance Journal. 1998. Vol. 13, No. 3. Pp. 154-158. DOI: 10.1002/(SICI)1099-1026(199805/06)13:3<154::AID-FFJ713>3.0.CO;2-2

124. Baldovini N., Tomi F., Casanova J. Enantiomeric differentiation of bornyl acetate by ${ }^{13} \mathrm{C}-\mathrm{NMR}$ using a chiral lanthanide shift reagent // Phytochemical Analysis. 2003. Vol. 14, No. 4. Pp. 241-244. DOI: 10.1002/pca.710

125. Ravid U., Putievsky E., Weinstein V., Ikan, R. Determination of the enantiomeric composition of natural flavouring agents by ${ }^{1}$ H-NMR spectroscopy // Essential Oils and Aromatic Plants: Proceedings of the 15th International Symposium on Essential Oils, held in Noordwijkerhout, The Netherlands, July 19-21, 1984. Springer Netherlands. 1985. Pp. 135-138. DOI: $10.1007 / 978-94-009-5137-2 \_11$ 
126. Lanfranchi D.A., Tomi F., Casanova J. Enantiomeric differentiation of atropine/hyoscyamine by ${ }^{13} \mathrm{C}$ NMR spectroscopy and its application to Datura stramonium extract // Phytochemical Analysis. 2010. Vol. 21, No. 6. Pp. 597-601. DOI: $10.1002 /$ pca. 1240

127. Weinstein V., Ikan R., Ravid U., Putievsky E. Determination of the enantiomeric composition of synthetic flavouring agents by ${ }^{1} \mathrm{H}-\mathrm{NMR}$ spectroscopy // Essential Oils and Aromatic Plants: Proceedings of the 15th International Symposium on Essential Oils, held in Noordwijkerhout, The Netherlands, July 19-21, 1984. Springer Netherlands. 1985. Pp. 139-143. DOI: $10.1007 / 978-94-009-5137-2 \quad 12$

128. Wenzel T.J., Wilcox J.D. Chiral reagents for the determination of enantiomeric excess and absolute configuration using NMR spectroscopy // Chirality. 2003. Vol. 15, No. 3. Pp. 256-270. DOI: 10.1002/chir.10190

129. Wenzel T.J., Chisholm C.D. Assignment of absolute configuration using chiral reagents and NMR spectroscopy // Chirality. 2011. Vol. 23, No. 3. Pp. 190-214. DOI: 10.1002/chir.20889

130. Silva M.S. Recent Advances in Multinuclear NMR Spectroscopy for Chiral Recognition of Organic Compounds // Molecules. 2017. Vol. 22, No. 2. DOI: 10.3390/molecules22020247

131. Guiochon G., Guillemin C. Quantitative Gas Chromatography for Laboratory Analyses and On-Line Process Control. Elsevier Science. 1988. 796 p.

132. Cuadros-Rodríguez L., Bagur-González M. G., Sánchez-Viñas M., González-Casado A., Gómez-Sáez A. M. Principles of analytical calibration/quantification for the separation sciences // Journal of Chromatography A. 2007. Vol. 1158, No. 1-2. Pp. 33-46. DOI: 10.1016/j.chroma.2007.03.030

133. Ortiz M., Sarabia L. Quantitative determination in chromatographic analysis based on n-way calibration strategies // Journal of Chromatography A. 2007. Vol. 1158, No. 1-2. Pp. 94-110. DOI: 10.1016/j.chroma.2007.04.047

134. Hibbert D.B. Systematic errors in analytical measurement results // Journal of Chromatography A. 2007. Vol. 1158, No. 1-2. Pp. 25-32. DOI: 10.1016/j.chroma.2007.03.021

135. Maroto A., Boqué R., Riu J., Rius F. Evaluating uncertainty in routine analysis // TrAC Trends in Analytical Chemistry. 1999. Vol. 18, No. 9-10. Pp. 577-584. DOI: 10.1016/S0165-9936(99)00151-X

136. Maroto A., Riu J., Boqué R., Rius F.X. Estimating uncertainties of analytical results using information from the validation process // Analytica Chimica Acta. 1999. Vol. 391, No. 2. Pp. 173-185. DOI: 10.1016/S0003-2670(99)00111-7

137. Meyer V.R. Measurement uncertainty // Journal of Chromatography A. 2007. Vol. 1158, No. 1-2. Pp. 15-24. DOI: $10.1016 /$ j.chroma.2007.02.082

138. González A.G., Herrador M.Á. A practical guide to analytical method validation, including measurement uncertainty and accuracy profiles // TrAC Trends in Analytical Chemistry. 2007. Vol. 26, No. 3. Pp. 227-238. DOI: $10.1016 /$ j.trac.2007.01.009

139. Feinberg M. Validation of analytical methods based on accuracy profiles // Journal of Chromatography A. 2007. Vol. 1158, No. 1-2. Pp. 174-183. DOI: 10.1016/j.chroma.2007.02.021

140. Vanatta L., Coleman D. Calibration, uncertainty, and recovery in the chromatographic sciences // Journal of Chromatography A. 2007. Vol. 1158, No. 1-2. Pp. 47-60. DOI: 10.1016/j.chroma.2007.02.040

141. Bicchi C., Liberto E., Matteodo M., Sgorbini B., Mondello L., Zellner B. d., Costa R., Rubiolo P. Quantitative analysis of essential oils: a complex task // Flavour and Fragrance Journal. 2008. Vol. 23, No. 6. Pp. 382-391. DOI: 10.1002/ffj.1905

142. IOFI Working Group on Methods of Analysis Guidelines for the quantitative gas chromatography of volatile flavouring substances, from the Working Group on Methods of Analysis of the International Organization of the Flavor Industry (IOFI) // Flavour and Fragrance Journal. 2011. Vol. 26, No. 5. Pp. 297-299. DOI: 10.1002/ffj.2061

143. Столяров Б.В., Савинов И.М., Витенберг А.Г. Руководство к практическим работам по газовой хроматографии. 3-е изд. / под ред. Б.В. Иоффе. Л., 1988. 336 с.

144. Сакодынский К.И., Бражников В.В., Волков С.А., Зельвенский В.Ю., Ганкина Э.С., Шатц В.Д. Аналитическая хроматография. М., 1993. $464 \mathrm{c}$.

145. Столяров Б.В., Савинов И.М., Витенберг А.Г., Карцова Л.А., Зенкевич И.Г., Калмановский В.И., Каламбет Ю.А. Практическая газовая и жидкостная хроматография. СПб, 2002. 616 с.

146. Dietz W.A. Response factors for gas chromatographic analyses // Journal of Chromatographic Science. 1967. Vol. 5, No. 2. Pp. 68-71. DOI: 10.1093/chromsci/5.2.68

147. Raffa K.F., Steffeck R.J. Computation of response factors for quantitative analysis of monoterpenes by gas-liquid chromatography // Journal of Chemical Ecology. 1988. Vol. 14, No. 5. Pp. 1385-1390. DOI: 10.1007/BF01020142

148. Devaux P., Guiochon G. Variations of the response of the electron capture detector with carrier gas flow-rate // Journal of Chromatographic Science. 1969. Vol. 7, No. 9. Pp. 561-564. DOI: 10.1093/chromsci/7.9.561

149. Gislason J., Wharry S.M. Relative molar response factors for thermal conductivity detectors // Journal of Chromatographic Science. 2000. Vol. 38, No. 3. Pp. 129-132. DOI: 10.1093/chromsci/38.3.129

150. Бражников В.В. Детекторы для хроматографии. М., 1992. 320 с.

151. Goedert M., Guiochon G. A study of the sources of error in quantitative gas chromatography: reproducibility of the response of a catharometer // Journal of Chromatographic Science. 1969. Vol. 7, No. 6. Pp. 323-339. DOI: $10.1093 /$ chromsci/7.6.323

152. Hoffmann E.G. Calculation to relative molar response factors of thermal conductivity detectors in gas chromatography // Analytical Chemistry. 1962. Vol. 34, No. 10. Pp. 1216-1222. DOI: 10.1021/ac60190a010

153. Herb S.F., Magidman P., Riemenschneider R.W. Observations on response factors for thermal conductivity detectors in GLC analysis of fatty acid methyl esters // Journal of the American Oil Chemists' Society. 1967. Vol. 44, No. 1. Pp. 32-36. DOI: 10.1007/BF02908367 
154. Liu F., Liang Y., Cao C. QSPR modeling of thermal conductivity detection response factors for diverse organic compound // Chemometrics and Intelligent Laboratory Systems. 2006. Vol. 81, No. 2. Pp. 120-126. DOI: 10.1016/j.chemolab.2005.10.004

155. Tong H.Y., Karasek F.W. Flame ionization detector response factors for compound classes in quantitative analysis of complex organic mixtures // Analytical Chemistry. 1984. Vol. 56, No. 12. Pp. 2124-2128. DOI: 10.1021/ac00276a033

156. Ackman R.G. The flame lonization detector: further comments on molecular breakdown and fundamental group responses // Journal of Chromatographic Science. 1968. Vol. 6, No. 10. Pp. 497-501. DOI: 10.1093/chromsci/6.10.497

157. Morvai M., Pályka I., Molnár-Perl I. Flame ionization detector response factors using the effective carbon number concept in the quantitative analysis of esters // Journal of Chromatographic Science. 1992. Vol. 30, No. 11. Pp. 448-452. DOI: $10.1093 /$ chromsci/30.11.448

158. Ulberth F., Gabernig R.G., Schrammel F. Flame-ionization detector response to methyl, ethyl, propyl, and butyl esters of fatty acids // Journal of the American Oil Chemists' Society. 1999. Vol. 76, No. 2. Pp. 263-266. DOI: 10.1007/s11746-9990228-7

159. Kimball B.A., Russell J.H., Griffin D.L., Johnston J.J. Response factor considerations for the quantitative analysis of Western Redcedar (Thuja plicata) foliar monoterpenes // Journal of Chromatographic Science. 2005. Vol. 43, No. 5. Pp. 253-258. DOI: 10.1093/chromsci/43.5.253

160. Scanlon J.T., Willis D.E. Calculation of flame ionization detector relative response factors using the effective carbon number concept // Journal of Chromatographic Science. 1985. Vol. 23, No. 8. Pp. 333-340. DOI: 10.1093/chromsci/23.8.333

161. Jones F.W. Estimation of flame-ionization detector relative response factors for oligomers of alkyl and aryl ether polyethoxylates using the effective carbon number concept // Journal of Chromatographic Science. 1998. Vol. 36, No. 5. Pp. 223-226. DOI: 10.1093/chromsci/36.5.223

162. Kállai M., Veres Z., Balla J. Response of flame ionization detectors to different homologous series // Chromatographia. 2001. Vol. 54, No. 7. Pp. 511-517. DOI: 10.1007/BF02491209

163. Slemr J., Slemr F., D'Souza H., Partridge R. Study of the relative response factors of various gas chromatograph-flame ionisation detector systems for measurement of $\mathrm{C}_{2}-\mathrm{C}_{9}$ hydrocarbons in air // Journal of Chromatography A. 2004 . Vol. 1061, No. 1. Pp. 75-84. DOI: 10.1016/j.chroma.2004.10.037

164. Szulejko J.E., Kim Y.-H., Kim K.-H. Method to predict gas chromatographic response factors for the trace-level analysis of volatile organic compounds based on the effective carbon number concept // Journal of Separation Science. 2013. Vol. 36, No. 20. Pp. 3356-3365. DOI: 10.1002/jssc.201300543

165. de Saint Laumer J.-Y., Cicchetti E., Merle P., Egger J., Chaintreau A. Quantification in gas chromatography: prediction of flame ionization detector response factors from combustion enthalpies and molecular structures // Analytical Chemistry. 2010. Vol. 82, No. 15. Pp. 6457-6462. DOI: 10.1021/ac1006574

166. Tissot E., Rochat S., Debonneville C., Chaintreau A. Rapid GC-FID quantification technique without authentic samples using predicted response factors // Flavour and Fragrance Journal. 2012. Vol. 27, No. 4. Pp. 290-296. DOI: $10.1002 / \mathrm{ffj} .3098$

167. de Saint Laumer J.-Y., Leocata S., Tissot E., Baroux L., Kampf D. M., Merle P., Boschung A., Seyfried M., Chaintreau A. Prediction of response factors for gas chromatography with flame ionization detection: Algorithm improvement, extension to silylated compounds, and application to the quantification of metabolites // Journal of Separation Science. 2015. Vol. 38, No. 18. Pp. 3209-3217. DOI: $10.1002 /$ jssc.201500106

168. Cao C., Huo P. Investigation of general expression to predict the molar response factor in the GC for monosubstituted alkanes // Journal of Chromatographic Science. 2007. Vol. 45, No. 6. Pp. 360-368. DOI: 10.1093/chromsci/45.6.360

169. Jalali-Heravi M., Fatemi M. Prediction of flame ionization detector response factors using an artificial neural network // Journal of Chromatography A. 1998. Vol. 825, No. 2. Pp. 161-169. DOI: 10.1016/S0021-9673(98)00687-6

170. Balaban A.T. Highly discriminating distance-based topological index // Chemical Physics Letters. 1982. Vol. 89, No. 5. Pp. 399-404. DOI: 10.1016/0009-2614(82)80009-2

171. Jalali-Heravi M., Fatemi M. Prediction of thermal conductivity detection response factors using an artificial neural network // Journal of Chromatography A. 2000. Vol. 897, No. 1-2. Pp. 227-235. DOI: 10.1016/S0021-9673(00)00793-7

172. Dojahn J.G., Wentworth W., Deming S.N., Stearns S.D. Determination of percent composition of a mixture analyzed by gas chromatography: Comparison of a helium pulsed-discharge photoionization detector with a flame ionization detector // Journal of Chromatography A. 2001. Vol. 917, No. 1-2. Pp. 187-204. DOI: 10.1016/S0021-9673(01)00637-9

173. Хмельницкий Р.А., Бродский Е.С. Хромато-масс-спектрометрия. М., 1984. 216 с.

174. Ahn J.-W., Pandey S.K., Kim K.-H. Comparison of GC-MS calibration properties of volatile organic compounds and relative quantification without calibration standards // Journal of Chromatographic Science. 2011. Vol. 49, No. 1. Pp. 19-28. DOI: $10.1093 / \mathrm{chrsci} / 49.1 .19$

175. Göröcs N., Mudri D., Mátyási J., Balla J. The determination of GC-MS relative molar responses of some n-alkanes and their halogenated analogs // Journal of Chromatographic Science. 2013. Vol. 51, No. 2. Pp. 138-145. DOI: $10.1093 /$ chromsci/bms 118

176. Jenke D., Odufu A. Utilization of internal standard response factors to estimate the concentration of organic compounds leached from pharmaceutical packaging systems and application of such estimated concentrations to safety assessment // Journal of Chromatographic Science. 2012. Vol. 50, No. 3. Pp. 206-212. DOI: 10.1093/chromsci/bmr048

177. Davies S.R., Alamgir M., Chan B.K.H., Dang T., Jones K., Krishnaswami M., Luo Y., Mitchell P.S.R., Moawad M., Swan H., Tarrant G.J. The development of an efficient mass balance approach for the purity assignment of organic calibra- 
tion standards // Analytical and Bioanalytical Chemistry. 2015. Vol. 407, No. 26. Pp. 7983-7993. DOI: 10.1007/s00216015-8971-0

178. Davies S.R., Jones K., Goldys A., Alamgir M., Chan B.K.H., Elgindy C., Mitchell P.S.R., Tarrant G.J., Krishnaswami M.R., Luo Y., Moawad M., Lawes D., Hook J.M. Purity assessment of organic calibration standards using a combination of quantitative NMR and mass balance // Analytical and Bioanalytical Chemistry. 2015. Vol. 407, No. 11. Pp. $3103-3113$. DOI: $10.1007 / \mathrm{s} 00216-014-7893-6$

179. Guillemin C.L., Auricourt M.F., Du Crest J., Vermont J. Accurate and rapid method for obtaining substance-specific correction factors usable in quantitative analysis by gas chromatography // Journal of Chromatographic Science. 1969. Vol. 7, No. 8. Pp. 493-499. DOI: 10.1093/chromsci/7.8.493

180. Estell R., Utsumi S., Cibils A. Measurement of monoterpenes and sesquiterpenes in serum, plasma, and rumen fluid from sheep // Animal Feed Science and Technology. 2010. Vol. 158, No. 1-2. Pp. 104-109. DOI: 10.1016/j.anifeedsci.2010.03.011

181. González-Bravo L., Marrero-Delange D., González-Guevara J. Group method approach to the estimation of response factors of unavailable substances in quantitative gas chromatography // Journal of Chromatography A. 2000. Vol. 888, No. 12. Pp. 159-173. DOI: $10.1016 / \mathrm{S} 0021-9673(00) 00541-0$

182. Pauli G.F. qNMR - a versatile concept for the validation of natural product reference compounds // Phytochemical Analysis. 2001. Vol. 12, No. 1. Pp. 28-42. DOI: 10.1002/1099-1565(200101/02)12:1<28::AID-PCA549>3.0.CO;2-D

183. Singh S., Roy R. The application of absolute quantitative ${ }^{1} \mathrm{H}$ NMR spectroscopy in drug discovery and development // Expert Opinion on Drug Discovery. 2016. Vol. 11, No. 7. Pp. 695-706. DOI: 10.1080/17460441.2016.1189899

184. Chauthe S.K., Sharma R.J., Aqil F., Gupta R.C., Singh I.P. Quantitative NMR: an applicable method for quantitative analysis of medicinal plant extracts and herbal products // Phytochemical Analysis. 2012. Vol. 23, No. 6. Pp. 689-696. DOI: $10.1002 /$ pca. 2375

185. Simmler C., Napolitano J.G., McAlpine J.B., Chen S.-N., Pauli G.F. Universal quantitative NMR analysis of complex natural samples // Current Opinion in Biotechnology. 2014. Vol. 25. Pp. 51-59. DOI: 10.1016/j.copbio.2013.08.004

186. Mo H., Harwood J., Zhang S., Xue Y., Santini R., Raftery D.R. A quantitative measure of NMR signal receiving efficiency // Journal of Magnetic Resonance. 2009. Vol. 200, No. 2. Pp. 239-244. DOI: 10.1016/j.jmr.2009.07.004

187. Buschhaus C., Jetter R. Composition differences between epicuticular and intracuticular wax substructures: How do plants seal their epidermal surfaces? // Journal of Experimental Botany. 2011. Vol. 62, No. 3. Pp. $841-853$. DOI: $10.1093 / \mathrm{jxb} / \mathrm{erq} 366$

188. Sweeney E.G., Thompson R.E., Ford D.C. GPC: calibration of normal paraffins by carbon number // Journal of Chromatographic Science. 1970. Vol. 8, No. 2. Pp. 76-81. DOI: 10.1093/chromsci/8.2.76

189. Stuckey C.L. Simulated true boiling point curves by gas liquid chromatography-selection of response factors // Journal of Chromatographic Science. 1978. Vol. 16, No. 10. Pp. 482-487. DOI: 10.1093/chromsci/16.10.482

190. Millar A.A., Smith M.A., Kunst L. All fatty acids are not equal: discrimination in plant membrane lipids // Trends in Plant Science. 2000. Vol. 5, No. 3. Pp. 95-101. DOI: 10.1016/S1360-1385(00)01566-1

191. Walley J.W., Kliebenstein D.J., Bostock R.M., Dehesh K. Fatty acids and early detection of pathogens // Current Opinion in Plant Biology. 2013. Vol. 16, No. 4. Pp. 520-526. DOI: 10.1016/j.pbi.2013.06.011

192. Reina-Pinto J.J., Yephremov A. Surface lipids and plant defenses // Plant Physiology and Biochemistry. 2009. Vol. 47, No. 6. Pp. 540-549. DOI: 10.1016/j.plaphy.2009.01.004

193. Ivankin A.N., Oliferenko G.L., Kulikovskii A.V., Chernukha I.M., Semenova A.A., Spiridonov K.I., Nasonova V.V. Determination of unsaturated fatty acids with a migrating double bond in complex biological matrices by gas chromatography with flame ionization and mass spectrometry detection // Journal of Analytical Chemistry. 2016. Vol. 71, No. 11. Pp. 11311137. DOI: $10.1134 / \mathrm{S} 1061934816110046$

194. Dodds E.D., McCoy M.R., Rea L.D., Kennish J.M. Gas chromatographic quantification of fatty acid methyl esters: Flame ionization detection vs. electron impact mass spectrometry // Lipids. 2005. Vol. 40, No. 4. Pp. 419-428. DOI: $10.1007 / \mathrm{s} 11745-006-1399-8$

195. Diehl J.W., DiSanzo F.P. Determination of total biodiesel fatty acid methyl, ethyl esters, and hydrocarbon types in diesel fuels by supercritical fluid chromatography-flame ionization detection // Journal of Chromatographic Science. 2007. Vol. 45, No. 10. Pp. 690-693. DOI: 10.1093/chromsci/45.10.690

196. Sobrado L.A., Freije-Carrelo L., Moldovan M., Encinar J. R., Alonso J.I.G. Comparison of gas chromatographycombustion-mass spectrometry and gas chromatography-flame ionization detector for the determination of fatty acid methyl esters in biodiesel without specific standards // Journal of Chromatography A. 2016. Vol. 1457. Pp. 134-143. DOI: 10.1016/j.chroma.2016.06.033

197. Cicchetti E., Merle P., Chaintreau A. Quantitation in gas chromatography: usual practices and performances of a response factor database // Flavour and Fragrance Journal. 2008. Vol. 23, No. 6. Pp. 450-459. DOI: 10.1002/ffj. 1906

198. Putievsky E., Ravid U., Husain S.Z. Differences in the yield of plant material, essential oils and their main components during the life cycle of Origanum vulgare L. // Essential Oils and Aromatic Plants: Proceedings of the 15th International Symposium on Essential Oils, held in Noordwijkerhout, The Netherlands, July 19-21, 1984. Springer Netherlands. 1985. Pp. 185-189. DOI: 10.1007/978-94-009-5137-2_20

199. Brunke E.-J., Hammerschmidt F.-J. Constituents of the essential oil of Salvia stenophylla - first identification of $(+)$-epi- $\alpha-$ bisabolol in nature // Essential Oils and Aromatic Plants: Proceedings of the 15th International Symposium on Essential Oils, held in Noordwijkerhout, The Netherlands, July 19-21, 1984. Springer Netherlands. 1985. Pp. 145-150. DOI: 10.1007/978-94-009-5137-2_13 
200. Verzár-Petri G., Then M., Mészáros S. Formation of essential oil in Clary Sage under different conditions // Essential Oils and Aromatic Plants: Proceedings of the 15th International Symposium on Essential Oils, held in Noordwijkerhout, The Netherlands, July 19-21, 1984. Springer Netherlands. 1985. Pp. 199-202. DOI: 10.1007/978-94-009-5137-2_22

201. Leocata S., Frank S., Wang Y., Calandra M. J., Chaintreau A. Quantification of hydroperoxides by gas chromatographyflame ionization detection and predicted response factors // Flavour and Fragrance Journal. 2016. Vol. 31, No. 4. Pp. 329335. DOI: $10.1002 / \mathrm{ffj} .3324$

202. Rudbäck J., Islam N., Nilsson U., Karlberg A.-T. A sensitive method for determination of allergenic fragrance terpene hydroperoxides using liquid chromatography coupled with tandem mass spectrometry // Journal of Separation Science. 2013. Vol. 36, No. 8. Pp. 1370-1378. DOI: 10.1002/jssc.201200855

203. Demyttenaere J.C.R. The new European Union Flavouring Regulation and its impact on essential oils: production of natural flavouring ingredients and maximum levels of restricted substances // Flavour and Fragrance Journal. 2012. Vol. 27, No. 1. Pp. 3-12. DOI: 10.1002/ffj.2093

204. Cachet T., Brevard H., Chaintreau A., Demyttenaere J., French L., Gassenmeier K., Joulain D., Koenig T., Leijs H., Liddle P., Loesing G., Marchant M., Merle P., Saito K., Schippa C., Sekiya F., Smith T. IOFI recommended practice for the use of predicted relative-response factors for the rapid quantification of volatile flavouring compounds by GC-FID // Flavour and Fragrance Journal. 2016. Vol. 31, No. 3. Pp. 191-194. DOI: 10.1002/ffj.3311

205. Cachet T., Brevard H., Cantergiani E., Chaintreau A., Demyttenaere J., French L., Gassenmeier K., Joulain D., Koenig T., Leijs H., Liddle P., Loesing G., Marchant M., Saito K., Scanlan F., Schippa C., Scotti A., Sekiya F., Sherlock A., Smith T. Determination of volatile 'restricted substances' in flavourings and their volatile raw materials by GC-MS // Flavour and Fragrance Journal. 2015. Vol. 30, No. 2. Pp. 160-164. DOI: 10.1002/ffj.3222

206. Sousa J.P.B., Brancalion A.P., Souza A.B., Turatti I.C., Ambrósio S.R., Furtado N.A., Lopes N.P., Bastos J.K. Validation of a gas chromatographic method to quantify sesquiterpenes in copaiba oils // Journal of Pharmaceutical and Biomedical Analysis. 2011. Vol. 54, No. 4. Pp. 653-659. DOI: 10.1016/j.jpba.2010.10.006

207. Zhu J.-J., An Y.-W., Hu G., Yin G.-P., Zhang Q.-W., Wang Z.-M. Simultaneous determination of multiple sesquiterpenes in Curcuma wenyujin herbal medicines and related products with one single reference standard // Molecules. 2013. Vol. 18, No. 2. Pp. 2110-2121. DOI: 10.3390/molecules 18022110

208. Joó É., Dewulf J., Demarcke M., Amelynck C., Schoon N., Müller J.-F., Šimpraga M., Steppe K., Langenhove H.V. Quantification of interferences in PTR-MS measurements of monoterpene emissions from Fagus sylvatica L. using simultaneous TD-GC-MS measurements // International Journal of Mass Spectrometry. 2010. Vol. 291, No. 1-2. Pp. 90-95. DOI: $10.1016 /$ j.jims.2010.01.018

209. Kang J.H., Kim M.E., Kim Y.D., Rhee Y.W., Lee S. Development of primary standard gas mixtures for monitoring monoterpenes ( $\alpha$-pinene, 3-carene, R-(+)-limonene, 1,8-cineole) ambient levels (at $2 \mathrm{nmol} / \mathrm{mol}$ ) // Journal of Korean Society for Atmospheric Environment. 2016. Vol. 32, No. 3. Pp. 320-328. DOI: 10.5572/KOSAE.2016.32.3.320

210. Arh G., Klasinc L., Veber M., Pompe M. Calibration of mass selective detector in non-target analysis of volatile organic compounds in the air // Journal of Chromatography A. 2011. Vol. 1218, No. 11. Pp. 1538-1543. DOI: 10.1016/j.chroma.2011.01.037

211. Faiola C.L., Erickson M.H., Fricaud V.L., Jobson B.T., VanReken T.M. Quantification of biogenic volatile organic compounds with a flame ionization detector using the effective carbon number concept // Atmospheric Measurement Techniques. 2012. Vol. 5, No. 8. Pp. 1911-1923. DOI: 10.5194/amt-5-1911-2012 


\section{Tkachev A.V. PROBLEMS OF QUALITATIVE AND QUANTITATIVE ANALYSIS OF PLANT VOLATILES}

N.N. Vorozhtsov Novosibirsk Institute of Organic Chemistry of Siberian Branch of Russian Academy of Sciences (NIOCH SB RAS), 9 Lavrentiev Avenue, Novosibirsk, 630090, Russia

Novosibirsk State University, 2 Pirogova str., Novosibirsk,630090, Russia, e-mail: atkachev@nioch.nsc.ru

Strategies for the analysis of plant volatiles have changed significantly over the past 15-20 years due to the introduction of new approaches to sample preparation and analysis, including approaches developed for other areas and currently applied to the analysis of plant metabolites. Any analysis of plant substances consists of two steps. The first step includes collection, primary processing, conservation, storage and extraction of plant material to prepare samples for research. The second step is the actual analysis of the samples by particular set of chromatographic, spectral and/or hybrid (hyphenated) techniques. Attention of scientific publications is usually focused on the second step, whereas the first step is "behind the scenes." However, it is at the first step that significant processes inside the biomaterial occur. It is impossible to correctly and adequately evaluate the final result of the research wthout regard to these processes. At both steps of research work, specific problems arise, the discussion of which is the subject of this review.

Wide distribution of the modern chromatographic instrumetns equipped with contemporary sofisticated software led to the fact that a significant part of the experiment is performed in an automatic mode. However, one must understand that improving the technique of the experiment does not change the basis of the method, and therefore does not eliminate the fundamental limitations of the method used. Therefore, to avoid errors in the publication of the results, all the experimental data obtained in an automatic mode should be subjected to an impartial revision by the experimenter taking into account all known limitations inherent in methods used for separation and detecting of components. In order to correctly interpret the data obtained, it is necessary to know the entire history of the sample under investigation, and for this, all manipulations with plant material — from collection of raw materials and to final sample preparation - must be carefully documented. Only in this case one can expect to receive meaningful research results.

Keywords: plant volatiles, gas chromatography, gas chromatography-mass spectrometry, qualitative analysis, quantitative analysis, detectors, standards, artifacts.

\section{References}

1. Bohlmann J. \& Keeling C.I. The Plant Journal, 2008, vol. 54, No. 4, pp. 656-669. DOI: 10.1111/j.1365313X.2008.03449.x

2. Schwab W., Davidovich-Rikanati R. \& Lewinsohn E. The Plant Journal, 2008, vol. 54, no. 4, pp. $712-732$. DOI: $10.1111 / \mathrm{j} .1365-313$ X.2008.03446.x

3. Morozov S.V., Tkacheva N.I., Tkachev A.V. Problemy kompleksnogo khimicheskogo profilirovaniia lekarstvennykh rastenii. Farmatsiia i farmakologiia. [Problems of complex chemical profiling of medicinal plants. Pharmacy and pharmacology]. 2017. (in press). (in Russ.).

4. Bicchi C., Cagliero C., Rubiolo P. Flavour and Fragrance Journal, 2011, vol. 26, no. 5, pp. 321-325. DOI: $10.1002 / \mathrm{ffj} .2059$

5. Sgorbini B., Cagliero C., Boggia L., Liberto E., Reichenbach S. E., Rubiolo P., Cordero C., Bicchi C. Flavour and Fragrance Journal, 2015, vol. 30, no. 5, pp. 366-380. DOI: 10.1002/ffj.3255

6. Harman-Ware A.E., Sykes R., Peter G.F., Davis M. Frontiers in Energy Research, 2016, vol. 4, pp. 2. DOI: $10.3389 /$ fenrg.2016.00002

7. Tranchida P. Q., Franchina F. A. \& Mondello L. Flavour and Fragrance Journal, 2017, vol. 32, no. 4, pp. $218-227$. DOI: $10.1002 /$ ffj.3383

8. Middleditch B.S. Analytical Artifacts: GC, MS, HPLC, TLC and PC. J. of Chromatography Library, vol. 44 Elsevier Science Ltd. 1989. 1033 p.

9. Jones W.P., Kinghorn A.D. Natural Products Isolation. Humana Press. 2005, pp. 323-351. DOI: 10.1385/1-59259-955-9:323

10. Tkachev A.V. Issledovanie letuchikh veshchestv rastenii. [Research of volatile substances of plants]. Novosibirsk, 2008, 969 p. (in Russ.).

11. Huopalahti R., Kesälahti E. Essential Oils and Aromatic Plants: Proceedings of the 15th International Symposium on Essential Oils, held in Noordwijkerhout, The Netherlands, July 19-21, 1984. Springer Netherlands. 1985, pp. 179-184. DOI: 10.1007/978-94-009-5137-2 19

12. Tkachev A.V., Koroliuk E.A., Iusubov M.S., Gur'ev A.M. Khimiia rastitel'nogo syr'ia, 2002, no. 1, pp. 19-30. (in Russ.).

13. Utsumi S.A., Cibils A.F., Estell R.E., Wang Y.-F. Rangeland Ecology \& Management, 2006, vol. 59, no. 6, pp. 668-673. DOI: 10.2111/06-010R1.1

14. Tkachev A.V., Prokusheva D.L., Domrachev D.V. Dikorastushchie efirnomaslichnye rasteniia Iuzhnoi Sibiri. [Wildgrowing essential oil plants of Southern Siberia]. Novosibirsk, 2017, 575 p. (in Russ.).

15. Kubeczka K.-H. Essential Oils and Aromatic Plants: Proceedings of the 15th International Symposium on Essential Oils, held in Noordwijkerhout, The Netherlands, July 19-21, 1984. Springer Netherlands. 1985, pp. 107-126. DOI: 10.1007/978-94-009-5137-2_9

16. Casteel D.A. Natural Product Reports, 1992, vol. 9, no. 4, pp. 289-312. DOI: 10.1039/NP9920900289

17. Casteel D.A. Natural Product Reports, 1999, vol. 16, no. 1, pp. 55-73. DOI: 10.1039/A705725C

18. Jung M., Kim H., Lee K., Park M. Mini Reviews in Medicinal Chemistry, 2003, vol. 3, no. 2, pp. $159-165$. DOI: $10.2174 / 1389557033405313$

19. Liu D.-Z., Liu J.-K. Natural Products and Bioprospecting, 2013. vol. 3, no. 5, pp. 161-206. DOI: 10.1007/s13659-013-0042-7

20. $\mathrm{Bu}$ M., Yang B.B., Hu L. Current medicinal chemistry, 2016, vol. 23, no. 4, pp. $383-405$. DOI: $10.2174 / 0929867323666151127200949$ 
21. Wolfenden R., Lu X., Young G. Journal of the American Chemical Society, 1998, vol. 120, no. 27, pp. $6814-6815$. DOI: $10.1021 / \mathrm{ja} 9813055$

22. Zhang W.L., Chen J.-P., Lam K.Y.-C., Zhan J.Y.-X., Yao P., Dong T.T.-X., Tsim K.W.-K. Evidence-Based Complementary and Alternative Medicine, 2014, vol. 2014. DOI: 10.1155/2014/608721

23. Bolarinwa I.F., Oke M.O., Olaniyan S.A., Ajala A.S. Toxicology - New Aspects to This Scientific Conundrum. InTech, 2016, pp. 179-191. DOI: 10.5772/64886

24. Schmaus G., Kubeczka K.-H. Essential Oils and Aromatic Plants: Proceedings of the 15th International Symposium on Essential Oils, held in Noordwijkerhout, The Netherlands, July 19-21, 1984. Springer Netherlands. 1985, pp. 127-134. DOI: 10.1007/978-94-009-5137-2_10

25. Baldermann S., Yang Z., Sakai M., Fleischmann P., Watanabe N. Floriculture and Ornamental Biotechnology, 2009, vol. 3, no. 1, pp. 89-97.

26. Jean F.-I., Garneau F.-X., Collin G.J., Bouhajib M., Zamir L.O. Journal of Essential Oil Research, 1993, vol. 5, no. 1, pp. 7-11. DOI: 10.1080/10412905.1993.9698163

27. Mastelić J., Miloš M., Kuštrak D., Radonić A. Croatica Chemica Acta, 1998. vol. 71, no. 1, pp. $147-154$. URL: http://hrcak.srce.hr/132332

28. Mastelić J., Miloš M., Kuštrak D., Radonić A. Croatica Chemica Acta, 2000, vol. 73, no. 2, pp. 585-593. URL: http://hrcak.srce.hr/132073

29. Politeo O., Jukic M., Milos M. Journal of Food Biochemistry, 2010, vol. 34, no. 1, pp. 129-141. DOI: 10.1111/j.17454514.2009.00269.x

30. Sgorbini B., Cagliero C., Pagani A., Sganzerla M., Boggia L., Bicchi C., Rubiolo P. Phytochemistry, 2015, vol. 117, pp. 296-305. DOI: 10.1016/j.phytochem.2015.06.017

31. Tissier A. The Plant Journal, 2012, vol. 70, no. 1, pp. 51-68. DOI: 10.1111/j.1365-313X.2012.04913.x

32. Lange M.B., Turner G.W. Plant Biotechnology Journal, 2013, vol. 11, no. 1, pp. 2-22. DOI: 10.1111/j.14677652.2012.00737.x

33. Schilmiller A.L., Last R.L., Pichersky E. The Plant Journal, 2008, vol. 54, no. 4, pp. 702-711. DOI: 10.1111/j.1365313X.2008.03432.x

34. Bicchi C., D' Amato A., Frattini C., Nano G. M., Cappelletti E., Caniato R. Journal of High Resolution Chromatography, 1985, vol. 8, no. 8, pp. 431-435. DOI: 10.1002/jhrc. 1240080815

35. Fischer N., Nitz S., Drawert F. Flavour and Fragrance Journal, 1987, vol. 2, no. 2, pp. 55-61. DOI: 10.1002/ffj.2730020204

36. Toyota M., Koyama H., Mizutani M., Asakawa Y. Phytochemistry, 1996, vol. 41, no. 5, pp. 1347-1350. DOI: 10.1016/00319422(95)00798-9

37. Holloway P.J. The plant cuticle. Academic Press, London New York. 1982, pp. 45-84.

38. Boom A., Damsté J.S., de Leeuw J. Organic Geochemistry, 2005, vol. 36, no. 4, pp. 595-601. DOI: $10.1016 /$ j.orggeochem.2004.10.017

39. Valkama E., Salminen J.-P., Koricheva J., Pihlaja K. Annals of Botany, 2003, vol. 91, no. 6, pp. $643-655$. DOI: $10.1093 / \mathrm{aob} / \mathrm{mcg} 070$

40. Guhling O., Kinzler C., Dreyer M., Bringmann G., Jetter R. Journal of Chemical Ecology, 2005, vol. 31, no. 10, pp. $2323-2341$. DOI: $10.1007 / \mathrm{s} 10886-005-7104-1$

41. Can Baser K.H., Buchbauer G. Handbook of Essential Oils: Science, Technology, and Applications. Second Edition. CRC Press. 2016. 1095 p.

42. Matura M., Sköld M., Börje A., Andersen K.E., Bruze M., Frosch P., Goossens A., Johansen J.D., Svedman C., White I.R., Karlberg A.-T. Contact Dermatitis, 2005, vol. 52, no. 6, pp. 320-328. DOI: 10.1111/j.0105-1873.2005.00605.x

43. Christensson J.B., Matura M., Gruvberger B., Bruze M., Karlberg A.-T. Contact Dermatitis, 2010, vol. 62, no. 1, pp. 32-41. DOI: $10.1111 / \mathrm{j} .1600-0536.2009 .01657 . \mathrm{x}$

44. Bråred Christensson J., Andersen K.E., Bruze M., Johansen J.D., Garcia-Bravo B., Gimenez Arnau A., Goh C.-L., Nixon R., White I.R. Contact Dermatitis, 2012, vol. 67, no. 5, pp. 247-259. DOI: 10.1111/j.1600-0536.2012.02134.x

45. Bråred Christensson J., Karlberg A.-T., Andersen K.E., Bruze M., Johansen J.D., Garcia-Bravo B., Giménez Arnau A., Goh C.-L., Nixon R., White I.R. Contact Dermatitis, 2016, vol. 74, no. 5, pp. 273-280. DOI: 10.1111/cod.12545

46. Sköld M., Hagvall L., Karlberg A.-T. Contact Dermatitis, 2008, vol. 58, no. 1, pp. 9-14. DOI: 10.1111/j.16000536.2007.01262.x

47. Hagvall L., Berglund V., Bråred Christensson J. Contact Dermatitis, 2015, vol. 72, no. 4, pp. $216-223$. DOI: $10.1111 / \operatorname{cod} .12350$

48. Matura M., Goossens A., Bordalo O., Garcia-Bravo B., Magnusson K., Wrangsjö K., Karlberg A.-T. Contact Dermatitis, 2003, vol. 49, no. 1, pp. 15-21. DOI: 10.1111/j.0105-1873.2003.00135.x

49. Matura M., Sköld M., Börje A., Andersen K.E., Bruze M., Frosch P., Goossens A., Johansen J.D., Svedman C., White I.R., Karlberg A.-T. Contact Dermatitis, 2006, vol. 55, no. 5, pp. 274-279. DOI: 10.1111/j.1600-0536.2006.00939.x

50. Christensson J.B., Johansson S., Hagvall L., Jonsson C., Börje A. \& Karlberg A.-T. Contact Dermatitis, 2008, vol. 59, no. 6, pp. 344-352. DOI: 10.1111/j.1600-0536.2008.01442.x

51. Bråred Christensson J., Andersen K.E., Bruze M., Johansen J.D., Garcia-Bravo B., Giménez-Arnau A., Goh C.-L., Nixon R., White I.R. Contact Dermatitis, 2013, vol. 68, no. 4, pp. 214-223. DOI: 10.1111/cod.12036

52. Bråred Christensson J., Hellsén S., Börje A., Karlberg A.-T. Contact Dermatitis, 2014, vol. 70, no. 5, pp. $291-299$. DOI: $10.1111 /$ cod. 12195 
53. Niklasson I.B., Delaine T., Islam M.N., Karlsson R., Luthman K., Karlberg A.-T. Contact Dermatitis, 2013, vol. 68, no. 3, pp. 129-138. DOI: 10.1111/cod.12009

54. Rudbäck J., Hagvall L., Börje A., Nilsson U., Karlberg A.-T. Contact Dermatitis, 2014, vol. 70, no. 6, pp. $329-339$. DOI: $10.1111 /$ cod.12234

55. Hagvall L., Sköld M., Bråred-Christensson J., Börje A. \& Karlberg A.-T. Contact Dermatitis, 2008, vol. 59, no. 3, pp. 143-150. DOI: 10.1111/j.1600-0536.2008.01402.x

56. Njoroge S.M., Ukeda H., Sawamura M. Journal of Agricultural and Food Chemistry, 1996, vol. 44, no. 2, pp. 550-556. DOI: $10.1021 / \mathrm{jf} 950284 \mathrm{k}$

57. Njoroge S.M., Ukeda H., Sawamura M. Journal of Agricultural and Food Chemistry, 2003, vol. 51, no. 14, pp. 4029-4035. DOI: $10.1021 / \mathrm{jf0} 21215 \mathrm{q}$

58. Sun H., Ni H., Yang Y., Wu L., Cai H.-n., Xiao A.-f., Chen F. Journal of Agricultural and Food Chemistry, 2014, vol. 62, no. 49, pp. 11818-11830. DOI: 10.1021/jf504294g

59. Turek C., Stintzing F.C. Journal of Food Science, 2011, vol. 76, no. 9, pp. C1365-C1375. DOI: 10.1111/j.17503841.2011.02416.x

60. Turek C., Stintzing F.C. Comprehensive Reviews in Food Science and Food Safety, 2013, vol. 12, no. 1, pp. 40-53. DOI: $10.1111 / 1541-4337.12006$

61. Kashiwagi T., Lan Phi N.T., Sawamura M. Food Science and Technology Research, 2010, vol. 16, no. 1, pp. 51-58. DOI: $10.3136 /$ fstr. 16.51

62. Takeda K., Horibe I., Minato H. J. Chem. Soc. D., 1971, no. 7, pp. 308. DOI: 10.1039/C29710000308

63. Reichardt P.B., Anderson B.J., Clausen T.P., Hoskins L.C. Canadian Journal of Chemistry, 1989, vol. 67, no. 7, pp. $1174-1177$. DOI: $10.1139 / \mathrm{v} 89-177$

64. Garcia G., Charmillon J.-M., Roux E., Sutour S., Rakotozafy J. B., Désiré O., Paoli M., Tomi F., Rabehaja D.J.R. Journal of Essential Oil Research, 2017, vol. 29, no. 3, pp. 214-220. DOI: 10.1080/10412905.2016.1251982

65. Rabe P., Barra L., Rinkel J., Riclea R., Citron C.A., Klapschinski T.A., Janusko A., Dickschat J.S. Angewandte Chemie International Edition, 2015, vol. 54, no. 45, pp. 13448-13451. DOI: 10.1002/anie.201507615

66. Nilsson J., Carlberg J., Abrahamsson P., Hulthe G., Persson B.-A., Karlberg A.-T. Rapid Communications in Mass Spectrometry, 2008, vol. 22, no. 22, pp. 3593-3598. DOI: 10.1002/rcm.3770

67. Valcárcel M., Cárdenas S., Simonet B., Carrillo-Carrión C. Journal of Chromatography A., 2007, vol. 1158, no. 1-2, pp. 234-240. DOI: 10.1016/j.chroma.2007.03.034

68. Stashenko E.E., Martínez J.R. Gas Chromatography in Plant Science, Wine Technology, Toxicology and Some Specific Applications. InTech. 2012, pp. 247-270. DOI: 10.5772/32246

69. Chamorro E.R., Zambón S.N., Morales W.G., Sequeira A.F., Velasco G.A. Gas Chromatography in Plant Science, Wine Technology, Toxicology and Some Specific Applications. InTech. 2012, pp. 307-324. DOI: 10.5772/33201

70. Rubiolo P., Sgorbini B., Liberto E., Cordero C., Bicchi C. Flavour and Fragrance Journal, 2010, vol. 25, no. 5, pp. $282-290$. DOI: $10.1002 / \mathrm{ffj} .1984$

71. Jones C.E., Kato S., Nakashima Y., Kajii Y. Atmospheric Measurement Techniques, 2014, vol. 7, no. 5, pp. $1259-1275$. DOI: $10.5194 / \mathrm{amt}-7-1259-2014$

72. Kováts E. Helvetica Chimica Acta, 1958, vol. 41, no. 7, pp. 1915-1932. DOI: 10.1002/hlca.19580410703

73. Wick C.D., Siepmann J., Klotz W.L., Schure M.R. Journal of Chromatography A., 2002, vol. 954, no. 1, pp. $181-190$. DOI: $10.1016 / \mathrm{S} 0021-9673(02) 00171-1$

74. Héberger K. Journal of Chromatography A., 2007, vol. 1158, no. 1-2, pp. 273-305. DOI: 10.1016/j.chroma.2007.03.108

75. van den Dool H., Kratz P.D. Journal of Chromatography, 1963, vol. 11, pp. 463-471. DOI: 10.1016/S00219673(01)80947-X

76. Bicchi C., Binello A., D'Amato A., Rubiolo P. Journal of Chromatographic Science, 1999, vol. 37, no. 8, pp. $288-294$. DOI: $10.1093 /$ chromsci/37.8.288

77. Analytical Methods Committee Application of Gas-Liquid Chromatography to the Analysis of Essential Oils. Part XVII. Fingerprinting of Essential Oils by Temperature-programmed Gas-Liquid Chromatography Using Capillary Columns With Non-polar Stationary Phases // Analyst. 1997, vol. 122, pp. 1167-1174. DOI: 10.1039/A704651K

78. Adams R.P. Identification of Essential Oil Components by Gas Chromatography/Mass Spectroscopy, 4th Edition. Allured Publishing Corporation, Illinois, USA. 2007. 804 p.

79. Gonzalez F., Nardillo A. Journal of Chromatography A., 1999, vol. 842, no. 1, pp. 29-49. DOI: 10.1016/S00219673(99)00158-2

80. Ong R., Shellie R., Marriott P. Journal of Separation Science, 2001, vol. 24, no. 5, pp. 367-377. DOI: 10.1002/16159314(20010501)24:5<367::AID-JSSC367>3.0.CO;2-U

81. Western R.J., Marriott P.J. Journal of Separation Science, 2002, vol. 25, no. 13, pp. 831-838. DOI: 10.1002/16159314(20020901)25:13<831::AID-JSSC832>3.0.CO;2-R

82. Zenkevich I.G. 100 Let khromatografii. [100 Years of chromatography]. Ed. B.A. Rudenko. Moscow, 2003, pp. 311-336. (in Russ.).

83. Egolf L.M., Jurs P.C. Analytical Chemistry, 1993, vol. 65, no. 21, pp. 3119-3126. DOI: 10.1021/ac00069a027

84. Kaliszan R., Bączek T. Recent Advances in QSAR Studies: Methods and Applications. Springer Netherlands. 2010, pp. 223-259. DOI: 10.1007/978-1-4020-9783-6_8

85. Todeschini R., Consonni V. Handbook of Molecular Descriptors. WILEY-VCH Verlag GmbH. 2000. 667 p. 
86. Beteringhe A., Radutiu A.C., Culita D.C., Mischie A., Spafiu F. QSAR \& Combinatorial Science, 2008, vol. 27, no. 8, pp. 996-1005. DOI: 10.1002/qsar.200730097

87. Ausloos P., Clifton C., Lias S., Mikaya A., Stein S., Tchekhovskoi D., Sparkman O., Zaikin V., Zhu D. Journal of the American Society for Mass Spectrometry, 1999, vol. 10, no. 4, pp. 287-299. DOI: 10.1016/S1044-0305(98)00159-7

88. Lebedev A.T. Mass-spektrometriia v organicheskoi khimii. [Mass spectrometry in organic chemistry]. Moscow, 2003, 493 p. (in Russ.).

89. McAndrew B.A. Perfumer \& Flavorist, 1992, vol. 17, no. 4, pp. 1-12.

90. Helmig D., Revermann T., Pollmann J., Kaltschmidt O., Hernández A. J., Bocquet F., David D. Journal of Chromatography A., 2003, vol. 1002, no. 1-2, pp. 193-211. DOI: 10.1016/S0021-9673(03)00619-8

91. Jacobsson U., Muddathir A.K. Phytochemistry, 1992, vol. 31, no. 12, pp. 4207-4211. DOI: 10.1016/0031-9422(92)80444-J

92. Zheng G.-Q., Kenney P.M., Lam L.K.T. Journal of Natural Products, 1992, vol. 55, no. 7, pp. $999-1003$. DOI: $10.1021 / \mathrm{np} 50085 \mathrm{a} 029$

93. Sabulal B., Dan M., Anil John J., Kurup R., Pradeep N.S., Valsamma R.K., George V. Phytochemistry, 2006, vol. 67, no. 22, pp. 2469-2473. DOI: 10.1016/j.phytochem.2006.08.003

94. Medeiros R., Passos G.F., Vitor C.E., Koepp J., Mazzuco T.L., Pianowski L.F., Campos M.M., Calixto J.B. British Journal of Pharmacology, 2007, vol. 151, no. 5, pp. 618-627. DOI: 10.1038/sj.bjp.0707270

95. Gertsch J., Leonti M., Raduner S., Racz I., Chen J.-Z., Xie X.-Q., Altmann K.-H., Karsak M., Zimmer A. Proceedings of the National Academy of Sciences, 2008, vol. 105, no. 26, pp. 9099-9104. DOI: 10.1073/pnas.0803601105

96. Langhasova L., Hanusova V., Rezek J., Stohanslova B., Ambroz M., Kralova V., Vanek T., Lou J. D., Yun Z. L., Yang J., Skalova L. Industrial Crops and Products, 2014, vol. 59, pp. 20-26. DOI: 10.1016/j.indcrop.2014.04.018

97. Klauke A.-L., Racz I., Pradier B., Markert A., Zimmer A., Gertsch J., Zimmer A. European Neuropsychopharmacology, 2014, vol. 24, no. 4, pp. 608-620. DOI: 10.1016/j.euroneuro.2013.10.008

98. Gubiani J.R., Zeraik M.L., Oliveira C.M., Ximenes V.F., Nogueira C.R., Fonseca L.M., Silva D.H.S., Bolzani V.S., Araujo A.R. Journal of Natural Products, 2014, vol. 77, no. 3, pp. 668-672. DOI: 10.1021/np400825s

99. Sarpietro M.G., Sotto A.D., Accolla M.L., Castelli F. Thermochimica Acta, 2015, vol. 600, pp. 28-34. DOI: $10.1016 /$ j.tca.2014.11.029

100. Fidyt K., Fiedorowicz A., Strządała L., Szumny A. Cancer Medicine, 2016, vol. 5, no. 10, pp. $3007-3017$. DOI: $10.1002 / \mathrm{cam} 4.816$

101. Joulain D., König W.A. Atlas of Spectral Data of Sesquiterpene Hydrocarbons. EB-Verlag. 2001. 658 p.

102. Lemberkovics É., Verzár-Petri G. Essential Oils and Aromatic Plants: Proceedings of the 15th International Symposium on Essential Oils, held in Noordwijkerhout, The Netherlands, July 19-21, 1984. Springer Netherlands. 1985, pp. 103-105. DOI: 10.1007/978-94-009-5137-2_8

103. Sarker S.D., Nahar L. Natural Products Isolation. Humana Press. 2005, pp. 233-267. DOI: 10.1385/1-59259-955-9:233

104. Hubert J., Nuzillard J.-M., Renault J.-H. Phytochemistry Reviews, 2017, vol. 16, no. 1, pp. 55-95. DOI: 10.1007/s11101015-9448-7

105. Marriott P.J., Massil T., Hügel H. Journal of Separation Science, 2004, vol. 27, no. 15-16, pp. $1273-1284$. DOI: $10.1002 / \mathrm{jssc} .200401917$

106. Pang T., Zhu S., Lu X., Xu G. Journal of Separation Science, 2007, vol. 30, no. 6, pp. 868-874. DOI: 10.1002/jssc.200600471

107. Shellie R., Marriott P., Cornwell C. Journal of Separation Science, 2001, vol. 24, no. 10-11, pp. 823-830. DOI: 10.1002/1615-9314(20011101)24:10/11<823::AID-JSSC823>3.0.CO;2-H

108. Cagliero C., Sgorbini B., Cordero C., Liberto E., Rubiolo P., Bicchi C. Israel Journal of Chemistry, 2016, vol. 56, no. 11-12, pp. 925-939. DOI: 10.1002/ijch.201600091

109. Tkachev A.V. Russian Chemical Reviews, 2007, vol. 76, no. 10, pp. 951-969. DOI: 10.1070/RC2007v076n10ABEH003728

110. de Juan A., Tauler R. Journal of Chromatography A., 2007, vol. 1158, no. 1-2, pp. 184-195. DOI: 10.1016/j.chroma.2007.05.045

111. Baldovini N., Tomi F., Casanova J. Phytochemical Analysis, 2001, vol. 12, no. 1, pp. 58-63. DOI: 10.1002/10991565(200101/02)12:1<58::AID-PCA559>3.0.CO;2-9

112. Cavalli J.-F., Tomi F., Bernardini A.-F., Casanova J. Phytochemical Analysis, 2004, vol. 15, no. 5, pp. $275-279$. DOI: $10.1002 / \mathrm{pca} .761$

113. Blanc M.-C., Bradesi P., Casanova J. Phytochemical Analysis, 2005, vol. 16, no. 3, pp. 150-154. DOI: 10.1002/pca.834

114. Duquesnoy E., Castola V., Casanova J. Phytochemical Analysis, 2007, vol. 18, no. 4, pp. 347-353. DOI: 10.1002/pca.989

115. Ferrari B., Castilho P., Tomi F., Rodrigues A. I., do Ceu Costa M., Casanova J. Phytochemical Analysis, 2005, vol. 16, no. 2, pp. 104-107. DOI: 10.1002/pca.825

116. Duquesnoy E., Paoli M., Castola V., Bighelli A., Casanova J. Phytochemical Analysis, 2009, vol. 20, no. 3, pp. $246-252$. DOI: $10.1002 /$ pca. 1121

117. Ratcliffe R.G., Roscher A., Shachar-Hill Y. Progress in Nuclear Magnetic Resonance Spectroscopy, 2001, vol. 39, no. 4, pp. 267-300. DOI: 10.1016/S0079-6565(01)00035-8

118. Lerche M.H., Jensen P.R., Karlsson M., Meier S. Analytical Chemistry, 2015, vol. 87, no. 1, pp. $119-132$. DOI: $10.1021 / \operatorname{ac} 501467 \mathrm{x}$

119. Krishnan P., Kruger N. J., Ratcliffe R.G. Journal of Experimental Botany, 2005, vol. 56, no. 410, pp. $255-265$. DOI: $10.1093 / \mathrm{jxb} / \mathrm{eri010}$

120. Kim H.K., Choi Y.H., Verpoorte R. Nature Protocols, 2010, vol. 5, pp. 536-549. DOI: 10.1038/nprot.2009.237

121. Bligny R., Douce R. Current Opinion in Plant Biology, 2001, vol. 4, no. 3, pp. 191-196. DOI: 10.1016/S13695266(00)00160-6 
122. Eisenreich W., Bacher A. Phytochemistry, 2007, vol. 68, no. 22, pp. 2799-2815. DOI: 10.1016/j.phytochem.2007.09.028

123. Ristorcelli D., Tomi F., Casanova J. Flavour and Fragrance Journal, 1998, vol. 13, no. 3, pp. $154-158$. DOI: 10.1002/(SICI)1099-1026(199805/06)13:3<154::AID-FFJ713>3.0.CO;2-2

124. Baldovini N., Tomi F., Casanova J. Phytochemical Analysis, 2003, vol. 14, no. 4, pp. 241-244. DOI: 10.1002/pca.710

125. Ravid U., Putievsky E., Weinstein V., Ikan R. Essential Oils and Aromatic Plants: Proceedings of the 15th International Symposium on Essential Oils, held in Noordwijkerhout, The Netherlands, July 19-21, 1984. Springer Netherlands. 1985, pp. 135-138. DOI: 10.1007/978-94-009-5137-2_11

126. Lanfranchi D. A., Tomi F., Casanova J. Phytochemical Analysis, 2010, vol. 21, no. 6, pp. 597-601. DOI: 10.1002/pca.1240

127. Weinstein V., Ikan R., Ravid U., Putievsky E. Essential Oils and Aromatic Plants: Proceedings of the 15th International Symposium on Essential Oils, held in Noordwijkerhout, The Netherlands, July 19-21, 1984. Springer Netherlands. 1985, pp. 139-143. DOI: 10.1007/978-94-009-5137-2_12

128. Wenzel T.J., Wilcox J.D. Chirality, 2003, vol. 15, no. 3, pp. 256-270. DOI: 10.1002/chir.10190

129. Wenzel T.J., Chisholm C.D. Chirality, 2011, vol. 23, no. 3, pp. 190-214. DOI: 10.1002/chir.20889

130. Silva M.S. Molecules, 2017, vol. 22, no. 2. DOI: 10.3390/molecules22020247

131. Guiochon G., Guillemin C. Quantitative Gas Chromatography for Laboratory Analyses and On-Line Process Control. Elsevier Science. 1988. 796 p.

132. Cuadros-Rodríguez L., Bagur-González M. G., Sánchez-Viñas M., González-Casado A., Gómez-Sáez A.M. Journal of Chromatography A., 2007, vol. 1158, no. 1-2, pp. 33-46. DOI: 10.1016/j.chroma.2007.03.030

133. Ortiz M., Sarabia L. Journal of Chromatography A., 2007, vol. 1158, no. 1-2, pp. 94-110. DOI: 10.1016/j.chroma.2007.04.047

134. Hibbert D.B. Journal of Chromatography A., 2007, vol. 1158, no. 1-2, pp. 25-32. DOI: 10.1016/j.chroma.2007.03.021

135. Maroto A., Boqué R., Riu J., Rius F. TrAC Trends in Analytical Chemistry, 1999, vol. 18, no. 9-10, pp. 577-584. DOI: 10.1016/S0165-9936(99)00151-X

136. Maroto A., Riu J., Boqué R., Rius F.X. Analytica Chimica Acta, 1999, vol. 391, no. 2, pp. 173-185. DOI: 10.1016/S00032670(99)00111-7

137. Meyer V.R. Measurement uncertainty // Journal of Chromatography A. 2007, vol. 1158, no. 1-2, pp. 15-24. DOI: 10.1016/j.chroma.2007.02.082

138. González A.G., Herrador M.Á. TrAC Trends in Analytical Chemistryб 2007, vol. 26, no. 3, pp. $227-238$. DOI: $10.1016 /$ j.trac.2007.01.009

139. Feinberg M. Journal of Chromatography A., 2007, vol. 1158, no. 1-2, pp. 174-183. DOI: 10.1016/j.chroma.2007.02.021

140. Vanatta L., Coleman D. Journal of Chromatography A., 2007, vol. 1158, no. 1-2, pp. 47-60. DOI: 10.1016/j.chroma.2007.02.040

141. Bicchi C., Liberto E., Matteodo M., Sgorbini B., Mondello L., Zellner B. d., Costa R., Rubiolo P. Flavour and Fragrance Journal, 2008, vol. 23, no. 6, pp. 382-391. DOI: 10.1002/ffj.1905

142. IOFI Working Group on Methods of Analysis Guidelines for the quantitative gas chromatography of volatile flavouring substances, from the Working Group on Methods of Analysis of the International Organization of the Flavor Industry (IOFI). Flavour and Fragrance Journal, 2011, vol. 26, no. 5, pp. 297-299. DOI: 10.1002/ffj.2061

143. Stoliarov B.V., Savinov I.M., Vitenberg A.G. Rukovodstvo k prakticheskim rabotam po gazovoi khromatografii. [A guide to practical work on gas chromatography]. Ed. B.V. Ioffe. Leningrad, 1988, 336 p. (in Russ.).

144. Sakodynskii K.I., Brazhnikov V.V., Volkov S.A., Zel'venskii V.Iu., Gankina E.S., Shatts V.D. Analiticheskaia khromatografiia. [Analytical chromatography]. Moscow, 1993, 464 p. (in Russ.).

145. Stoliarov B.V., Savinov I.M., Vitenberg A.G., Kartsova L.A., Zenkevich I.G., Kalmanovskii V.I., Kalambet Iu.A. Prakticheskaia gazovaia i zhidkostnaia khromatografiia. [Practical gas and liquid chromatography]. St. Petersburg, 2002, 616 p. (in Russ.).

146. Dietz W.A. Journal of Chromatographic Science, 1967, vol. 5, no. 2, pp. 68-71. DOI: 10.1093/chromsci/5.2.68

147. Raffa K.F., Steffeck R.J. Journal of Chemical Ecology, 1988, vol. 14, no. 5, pp. 1385-1390. DOI: 10.1007/BF01020142

148. Devaux P., Guiochon G. Journal of Chromatographic Science, 1969, vol. 7, no. 9, pp. 561-564. DOI: 10.1093/chromsci/7.9.561

149. Gislason J., Wharry S.M. Journal of Chromatographic Science, 2000, vol. 38, no. 3, pp. $129-132$. DOI: $10.1093 /$ chromsci/38.3.129

150. Brazhnikov V.V. Detektory dlia khromatografii. [Detectors for chromatography]. Moscow, 1992. 320 p. (in Russ.).

151. Goedert M., Guiochon G. Journal of Chromatographic Science, 1969, vol. 7, no. 6, pp. 323-339. DOI: 10.1093/chromsci/7.6.323

152. Hoffmann E.G. Analytical Chemistry, 1962, vol. 34, no. 10, pp. 1216-1222. DOI: 10.1021/ac60190a010

153. Herb S.F., Magidman P., Riemenschneider R.W. Journal of the American Oil Chemists' Society, 1967, vol. 44, no. 1, pp. 32-36. DOI: 10.1007/BF02908367

154. Liu F., Liang Y., Cao C. Chemometrics and Intelligent Laboratory Systems, 2006, vol. 81, no. 2, pp. $120-126$. DOI: $10.1016 /$ j.chemolab.2005.10.004

155. Tong H.Y., Karasek F.W. Analytical Chemistry, 1984, vol. 56, no. 12, pp. 2124-2128. DOI: 10.1021/ac00276a033

156. Ackman R.G. Journal of Chromatographic Science, 1968, vol. 6, no. 10, pp. 497-501. DOI: 10.1093/chromsci/6.10.497

157. Morvai M., Pályka I., Molnár-Perl I. Journal of Chromatographic Science, 1992, vol. 30, no. 11, pp. 448-452. DOI: $10.1093 /$ chromsci/30.11.448

158. Ulberth F., Gabernig R.G., Schrammel F. Journal of the American Oil Chemists' Society, 1999, vol. 76, no. 2, pp. $263-266$. DOI: $10.1007 / \mathrm{s} 11746-999-0228-7$

159. Kimball B.A., Russell J.H., Griffin D.L., Johnston J.J. Journal of Chromatographic Science, 2005, vol. 43, no. 5, pp. $253-258$. DOI: $10.1093 /$ chromsci/43.5.253 
160. Scanlon J.T., Willis D.E. Journal of Chromatographic Science, 1985, vol. 23, no. 8, pp. 333-340. DOI: 10.1093/chromsci/23.8.333

161. Jones F.W. Journal of Chromatographic Science, 1998, vol. 36, no. 5, pp. 223-226. DOI: 10.1093/chromsci/36.5.223

162. Kállai M., Veres Z., Balla J. Chromatographia, 2001, vol. 54, no. 7, pp. 511-517. DOI: 10.1007/BF02491209

163. Slemr J., Slemr F., D'Souza H., Partridge R. Journal of Chromatography A., 2004, vol. 1061, no. 1, pp. 75-84. DOI: 10.1016/j.chroma.2004.10.037

164. Szulejko J.E., Kim Y.-H., Kim K.-H. Journal of Separation Science, 2013, vol. 36, no. 20, pp. 3356-3365. DOI: $10.1002 /$ jssc. 201300543

165. de Saint Laumer J.-Y., Cicchetti E., Merle P., Egger J., Chaintreau A. Analytical Chemistry, 2010, vol. 82, no. 15, pp. 6457-6462. DOI: 10.1021/ac1006574

166. Tissot E., Rochat S., Debonneville C., Chaintreau A. Flavour and Fragrance Journal, 2012, vol. 27, no. 4, pp. $290-296$. DOI: $10.1002 / \mathrm{ffj} .3098$

167. de Saint Laumer J.-Y., Leocata S., Tissot E., Baroux L., Kampf D. M., Merle P., Boschung A., Seyfried M., Chaintreau A. Journal of Separation Science, 2015, vol. 38, no. 18, pp. 3209-3217. DOI: 10.1002/jssc.201500106

168. Cao C., Huo P. Journal of Chromatographic Science, 2007, vol. 45, no. 6, pp. 360-368. DOI: 10.1093/chromsci/45.6.360

169. Jalali-Heravi M., Fatemi M. Journal of Chromatography A., 1998, vol. 825, no. 2, pp. 161-169. DOI: 10.1016/S00219673(98)00687-6

170. Balaban A.T. Chemical Physics Letters, 1982, vol. 89, no. 5, pp. 399-404. DOI: 10.1016/0009-2614(82)80009-2

171. Jalali-Heravi M., Fatemi M. Journal of Chromatography A., 2000, vol. 897, no. 1-2, pp. 227-235. DOI: 10.1016/S00219673(00)00793-7

172. Dojahn J.G., Wentworth W., Deming S.N., Stearns S.D. Journal of Chromatography A., 2001, vol. 917, no. 1-2, pp. $187-204$. DOI: $10.1016 /$ S0021-9673(01)00637-9

173. Khmel'nitskii R.A., Brodskii E.S. Khromato-mass-spektrometriia. [Chromato-mass spectrometry]. Moscow, 1984,216 p. (in Russ.).

174. Ahn J.-W., Pandey S.K., Kim K.-H. Journal of Chromatographic Science, 2011, vol. 49, no. 1, pp. 19-28. DOI: $10.1093 / \mathrm{chrsci} / 49.1 .19$

175. Göröcs N., Mudri D., Mátyási J., Balla J. Journal of Chromatographic Science, 2013, vol. 51, no. 2, pp. 138-145. DOI: $10.1093 /$ chromsci/bms118

176. Jenke D., Odufu A. Journal of Chromatographic Science, 2012, vol. 50, no. 3, pp. 206-212. DOI: 10.1093/chromsci/bmr048

177. Davies S.R., Alamgir M., Chan B.K.H., Dang T., Jones K., Krishnaswami M., Luo Y., Mitchell P.S.R., Moawad M., Swan H., Tarrant G.J. Analytical and Bioanalytical Chemistry, 2015, vol. 407, no. 26, pp. 7983-7993. DOI: 10.1007/s00216015-8971-0

178. Davies S.R., Jones K., Goldys A., Alamgir M., Chan B.K.H., Elgindy C., Mitchell P.S.R., Tarrant G.J., Krishnaswami M.R., Luo Y., Moawad M., Lawes D., Hook J.M. Analytical and Bioanalytical Chemistry, 2015, vol. 407, no. 11, pp. 3103-3113. DOI: 10.1007/s00216-014-7893-6

179. Guillemin C.L., Auricourt M.F., Du Crest J., Vermont J. Journal of Chromatographic Science, 1969, vol. 7, no. 8, pp. $493-499$. DOI: $10.1093 /$ chromsci/7.8.493

180. Estell R., Utsumi S., Cibils A. Animal Feed Science and Technology, 2010, vol. 158, no. 1-2, pp. 104-109. DOI: $10.1016 /$ j.anifeedsci.2010.03.011

181. González-Bravo L., Marrero-Delange D., González-Guevara J. Journal of Chromatography A., 2000, vol. 888, no. 1-2, pp. 159-173. DOI: 10.1016/S0021-9673(00)00541-0

182. Pauli G.F. Phytochemical Analysis, 2001, vol. 12, no. 1, pp. 28-42. DOI: 10.1002/1099-1565(200101/02)12:1<28::AIDPCA549>3.0.CO;2-D

183. Singh S., Roy R. Expert Opinion on Drug Discovery, 2016, vol. 11, no. 7, pp. 695-706. DOI: 10.1080/17460441.2016.1189899

184. Chauthe S.K., Sharma R.J., Aqil F., Gupta R.C., Singh I.P. Phytochemical Analysis, 2012, vol. 23, no. 6, pp. $689-696$. DOI: $10.1002 /$ pca. 2375

185. Simmler C., Napolitano J.G., McAlpine J.B., Chen S.-N., Pauli G.F. Current Opinion in Biotechnology, 2014, vol. 25, pp. 51-59. DOI: 10.1016/j.copbio.2013.08.004

186. Mo H., Harwood J., Zhang S., Xue Y., Santini R., Raftery D.R. Journal of Magnetic Resonance, 2009, vol. 200, no. 2, pp. 239-244. DOI: 10.1016/j.jmr.2009.07.004

187. Buschhaus C., Jetter R. Journal of Experimental Botany, 2011, vol. 62, no. 3, pp. 841-853. DOI: 10.1093/jxb/erq366

188. Sweeney E.G., Thompson R.E., Ford D.C. Journal of Chromatographic Science, 1970, vol. 8, no. 2, pp. 76-81. DOI: $10.1093 / \mathrm{chromsci} / 8.2 .76$

189. Stuckey C.L. Journal of Chromatographic Science, 1978, vol. 16, no. 10, pp. 482-487. DOI: 10.1093/chromsci/16.10.482

190. Millar A.A., Smith M.A., Kunst L. Trends in Plant Science, 2000, vol. 5, no. 3, pp. 95-101. DOI: 10.1016/S13601385(00)01566-1

191. Walley J.W., Kliebenstein D.J., Bostock R.M., Dehesh K. Current Opinion in Plant Biology, 2013, vol. 16, no. 4, pp. $520-526$. DOI: 10.1016/j.pbi.2013.06.011

192. Reina-Pinto J.J., Yephremov A. Plant Physiology and Biochemistry, 2009, vol. 47, no. 6, pp. 540-549. DOI: $10.1016 /$ j.plaphy.2009.01.004

193. Ivankin A.N., Oliferenko G.L., Kulikovskii A.V., Chernukha I.M., Semenova A.A., Spiridonov K.I., Nasonova V.V. Journal of Analytical Chemistry, 2016, vol. 71, no. 11, pp. 1131-1137. DOI: 10.1134/S1061934816110046 
194. Dodds E.D., McCoy M.R., Rea L.D., Kennish J.M. Lipids, 2005, vol. 40, no. 4, pp. 419-428. DOI: 10.1007/s11745-0061399-8

195. Diehl J.W., DiSanzo F.P. Journal of Chromatographic Science, 2007, vol. 45, no. 10, pp. 690-693. DOI: 10.1093/chromsci/45.10.690

196. Sobrado L.A., Freije-Carrelo L., Moldovan M., Encinar J. R., Alonso J.I.G. Journal of Chromatography A., 2016, vol. 1457, pp. 134-143. DOI: 10.1016/j.chroma.2016.06.033

197. Cicchetti E., Merle P., Chaintreau A. Flavour and Fragrance Journal, 2008, vol. 23, no. 6, pp. 450-459. DOI: 10.1002/ffj.1906

198. Putievsky E., Ravid U., Husain S.Z. Essential Oils and Aromatic Plants: Proceedings of the 15th International Symposium on Essential Oils, held in Noordwijkerhout, The Netherlands, July 19-21, 1984. Springer Netherlands. 1985, pp. $185-189$. DOI: 10.1007/978-94-009-5137-2_20

199. Brunke E.-J., Hammerschmidt F.-J. Essential Oils and Aromatic Plants: Proceedings of the 15th International Symposium on Essential Oils, held in Noordwijkerhout, The Netherlands, July 19-21, 1984. Springer Netherlands. 1985, pp. 145-150. DOI: 10.1007/978-94-009-5137-2_13

200. Verzár-Petri G., Then M., Mészáros S. Essential Oils and Aromatic Plants: Proceedings of the 15th International Symposium on Essential Oils, held in Noordwijkerhout, The Netherlands, July 19-21, 1984. Springer Netherlands. 1985, pp. $199-202$. DOI: 10.1007/978-94-009-5137-2_22

201. Leocata S., Frank S., Wang Y., Calandra M.J., Chaintreau A. Flavour and Fragrance Journal, 2016, vol. 31, no. 4, pp. 329-335. DOI: 10.1002/ffj.3324

202. Rudbäck J., Islam N., Nilsson U., Karlberg A.-T. Journal of Separation Science, 2013, vol. 36, no. 8, pp. $1370-1378$. DOI: $10.1002 /$ jssc. 201200855

203. Demyttenaere J.C.R. Flavour and Fragrance Journal, 2012, vol. 27, no. 1, pp. 3-12. DOI: 10.1002/ffj.2093

204. Cachet T., Brevard H., Chaintreau A., Demyttenaere J., French L., Gassenmeier K., Joulain D., Koenig T., Leijs H., Liddle P., Loesing G., Marchant M., Merle P., Saito K., Schippa C., Sekiya F., Smith T. Flavour and Fragrance Journal, 2016, vol. 31, no. 3, pp. 191-194. DOI: 10.1002/ffj.3311

205. Cachet T., Brevard H., Cantergiani E., Chaintreau A., Demyttenaere J., French L., Gassenmeier K., Joulain D., Koenig T., Leijs H., Liddle P., Loesing G., Marchant M., Saito K., Scanlan F., Schippa C., Scotti A., Sekiya F., Sherlock A., Smith T. Flavour and Fragrance Journal, 2015, vol. 30, no. 2, pp. 160-164. DOI: 10.1002/ffj.3222

206. Sousa J.P.B., Brancalion A.P., Souza A.B., Turatti I.C., Ambrósio S.R., Furtado N.A., Lopes N.P., Bastos J.K. Journal of Pharmaceutical and Biomedical Analysis, 2011, vol. 54, no. 4, pp. 653-659. DOI: 10.1016/j.jpba.2010.10.006

207. Zhu J.-J., An Y.-W., Hu G., Yin G.-P., Zhang Q.-W., Wang Z.-M. Molecules, 2013, vol. 18, no. 2, pp. $2110-2121$. DOI: $10.3390 /$ molecules 18022110

208. Joó É., Dewulf J., Demarcke M., Amelynck C., Schoon N., Müller J.-F., Šimpraga M., Steppe K., Langenhove H.V. International Journal of Mass Spectrometry, 2010, vol. 291, no. 1-2, pp. 90-95. DOI: 10.1016/j.ijms.2010.01.018

209. Kang J.H., Kim M.E., Kim Y.D., Rhee Y.W., Lee S. Journal of Korean Society for Atmospheric Environment, 2016, vol. 32, no. 3, pp. 320-328. DOI: 10.5572/KOSAE.2016.32.3.320

210. Arh G., Klasinc L., Veber M., Pompe M. Journal of Chromatography A., 2011, vol. 1218, no. 11, pp. $1538-1543$. DOI: 10.1016/j.chroma.2011.01.037

211. Faiola C.L., Erickson M.H., Fricaud V.L., Jobson B.T., VanReken T.M. Atmospheric Measurement Techniques, 2012 , vol. 5, no. 8, pp. 1911-1923. DOI: 10.5194/amt-5-1911-2012 

